\title{
Parenteral Anticoagulants
}

\section{Antithrombotic Therapy and Prevention of Thrombosis, 9th ed: American College of Chest Physicians Evidence-Based Clinical Practice Guidelines}

\author{
David A. Garcia, MD; Trevor P. Baglin, MBChB, PhD; Jeffrey I. Weitz, MD, FCCP; \\ and Meyer Michel Samama, MD
}

\begin{abstract}
This article describes the pharmacology of approved parenteral anticoagulants. These include the indirect anticoagulants, unfractionated heparin (UFH), low-molecular-weight heparins (LMWHs), fondaparinux, and danaparoid, as well as the direct thrombin inhibitors hirudin, bivalirudin, and argatroban. UFH is a heterogeneous mixture of glycosaminoglycans that bind to antithrombin via a unique pentasaccharide sequence and catalyze the inactivation of thrombin, factor Xa, and other clotting enzymes. Heparin also binds to cells and plasma proteins other than antithrombin causing unpredictable pharmacokinetic and pharmacodynamic properties and triggering nonhemorrhagic side effects, such as heparin-induced thrombocytopenia (HIT) and osteoporosis. LMWHs have greater inhibitory activity against factor $\mathrm{Xa}$ than thrombin and exhibit less binding to cells and plasma proteins than heparin. Consequently, LMWH preparations have more predictable pharmacokinetic and pharmacodynamic properties, have a longer half-life than heparin, and are associated with a lower risk of nonhemorrhagic side effects. LMWHs can be administered once daily or bid by subcutaneous injection, without coagulation monitoring. Based on their greater convenience, LMWHs have replaced UFH for many clinical indications. Fondaparinux, a synthetic pentasaccharide, catalyzes the inhibition of factor $\mathrm{Xa}$, but not thrombin, in an antithrombin-dependent fashion. Fondaparinux binds only to antithrombin. Therefore, fondaparinux-associated HIT or osteoporosis is unlikely to occur. Fondaparinux exhibits complete bioavailability when administered subcutaneously, has a longer half-life than LMWHs, and is given once daily by subcutaneous injection in fixed doses, without coagulation monitoring. Three additional parenteral direct thrombin inhibitors and danaparoid are approved as alternatives to heparin in patients with HIT.

CHEST 2012; 141(2)(Suppl):e24S-e43S

Abbreviations: aPTT $=$ activated partial thromboplastin time; $\mathrm{AT}=$ antithrombin; $\mathrm{CrCl}=$ creatinine clearance; HCII = heparin cofactor II; HIT = heparin-induced thrombocytopenia; INR = international normalized ratio; $\mathrm{LMWH}=$ low-molecular-weight heparin; $\mathrm{PF} 4=$ platelet factor 4; $\mathrm{RR}=$ relative risk; $\mathrm{UFH}=$ unfractionated heparin
\end{abstract}

$\mathbf{T}^{\mathrm{T}}$ his article focuses on parenteral anticoagulants in current use. These agents can be divided into indirect anticoagulants whose activity is mediated by plasma cofactors and direct anticoagulants that do not require plasma cofactors to express their activity. The indirect parenteral anticoagulants in current use include heparin, low-molecular-weight-heparins (LMWHs), fondaparinux, and danaparoid. These drugs have little or no intrinsic anticoagulant activity, and exert their anticoagulant activity by potentiating antithrombin (AT), an endogenous inhibitor of various activated clotting factors. The parenteral direct anticoagulants in current use all target thrombin. These agents include recombinant hirudins, bivalirudin, and argatroban.

\subsection{Indirect PARENTERAL Anticoagulants}

\subsection{Heparin}

More than 90 years ago, McLean ${ }^{1}$ discovered that heparin has anticoagulant properties. Brinkhous and associates $^{2}$ then demonstrated that heparin requires a plasma cofactor to express its anticoagulant activity. 
In 1968, Abildgaard identified this cofactor as antithrombin III, ${ }^{3}$ which is now referred to as antithrombin. The major anticoagulant action of heparin is mediated by the heparin/AT interaction. The mechanism of this interaction was demonstrated in the 1970s. ${ }^{4-6}$ Heparin binds to positively charged residues on AT, producing a conformational change at the AT arginine reactive center that converts AT from a slow to a rapid inhibitor of serine proteases. The arginine reactive center on AT binds covalently to the active center serine of thrombin and other coagulation enzymes, thereby irreversibly inhibiting their procoagulant activity. ${ }^{5}$ Heparin then dissociates from AT and is reused (Fig 1). ${ }^{7}$

\subsubsection{Structure and Mechanism of Action: Heparin} is a highly sulfated mucopolysaccharide. It is heterogeneous with respect to molecular size, anticoagulant activity, and pharmacokinetic properties (Table 1). Heparin molecules range in molecular weight from 3,000 to $30,000 \mathrm{kDa}$ with a mean of 15,000 , which corresponds to approximately 45 saccharide units (Fig 2). ${ }^{8-10}$ Only about one-third of the heparin molecules possess the unique pentasaccharide sequence and it is this fraction that is responsible for most of the anticoagulant effect of heparin. ${ }^{8,11}$ Heparin chains that lack the pentasaccharide sequence have minimal anticoagulant activity when heparin is given in therapeutic concentrations. However, at concentrations higher than those usually administered clinically, heparin chains with or without the pentasaccharide sequence can catalyze thrombin inhibition by heparin cofactor II (HCII), a second plasma cofactor. ${ }^{12}$

Revision accepted August 31, 2011

Affiliations: From the University of New Mexico (Dr Garcia), Albuquerque, NM; the Cambridge University Hospitals NHS Trust (Dr Baglin), Addenbrooke's Hospital, Cambridge, England; the Thrombosis and Atherosclerosis Research Institute and McMaster University (Dr Weitz), Hamilton, ON, Canada; and the Hotel Dieu University Hospital (Dr Samama), Place du Parvis Notre Dame, Paris, France.

Funding/Support: The Antithrombotic Therapy and Prevention of Thrombosis, 9th ed: American College of Chest Physicians Evidence-Based Clinical Practice Guidelines received support from the National Heart, Lung, and Blood Institute [R13 HL104758] and Bayer Schering Pharma AG. Support in the form of educational grants was also provided by Bristol-Myers Squibb; Pfizer, Inc; Canyon Pharmaceuticals; and sanofi-aventis US.

Disclaimer: American College of Chest Physician guidelines are intended for general information only, are not medical advice, and do not replace professional medical care and physician advice, which always should be sought for any medical condition. The complete disclaimer for this guideline can be accessed at http://chestjournal.chestpubs.org/content/141/2_suppl/1S.

Correspondence to: David A. Garcia, MD, 1 University of New Mexico, MSC07-4025, Albuquerque, NM 87131; e-mail: davgarcia@ salud.unm.edu

(C) 2012 American College of Chest Physicians. Reproduction of this article is prohibited without written permission from the American College of Chest Physicians (http://www.chestpubs.org/ site/misc/reprints.xhtml).

DOI: $10.1378 /$ chest.11-2291
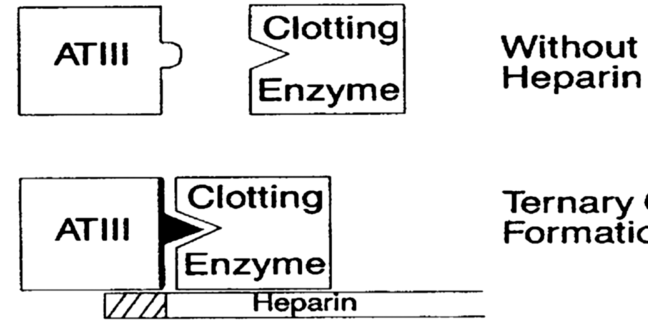

\section{Ternary Complex Formation}

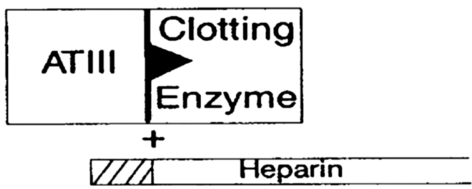

\author{
Dissociation of \\ Heparin
}

FIGURE 1. Inactivation of clotting enzymes by heparin. Top, ATIII is a slow inhibitor without heparin. Middle, Heparin binds to ATIII through a high-affinity pentasaccharide and induces a conformational change in ATIII, thereby converting ATIII from a slow inhibitor to a very rapid inhibitor. Bottom, ATIII binds covalently to the clotting enzyme, and the heparin dissociates from the complex and can be reused. AT = antithrombin. (Reprinted with permission from Hirsh et al. ${ }^{7}$ )

At even higher concentrations, low-affinity heparin impairs factor Xa generation through AT- and HCIIindependent mechanisms ${ }^{13}$ (Table 2).

The heparin/AT complex inactivates thrombin (factor IIa) and factors Xa, IXa, XIa, and XIIa. ${ }^{5}$ Heparin catalyzes AT-mediated thrombin inhibition in a nonspecific charge-dependent fashion to form a ternary heparin/AT/thrombin complex. In contrast, to catalyze factor Xa inhibition by AT, heparin needs only to bind to AT. ${ }^{14}$ In both cases binding occurs at the unique pentasaccharide sequence found within some heparin molecules. Heparin chains consisting of $<18$ saccharide units are too short to bridge AT to thrombin. Consequently, these chains are unable to catalyze thrombin inhibition. However, short heparin chains can catalyze inhibition of factor Xa by AT. ${ }^{15-18}$ By inactivating thrombin or attenuating its generation, heparin not only prevents fibrin formation but also inhibits thrombin-induced activation of platelets and factors V, VIII, and XI. ${ }^{19-21}$

The interaction of heparin with HCII is charge dependent, but pentasaccharide independent. Catalysis

Table 1-Molecular Size, Anticoagulant Activity, and Pharmacokinetic Properties of Heparin

\begin{tabular}{lc}
\hline \hline Attribute & Characteristics \\
\hline Molecular size & $\begin{array}{c}\text { Mean molecular weight, 15,000 kDa } \\
\text { (range, 3,000-30,000) }\end{array}$ \\
\hline $\begin{array}{l}\text { Anticoagulant } \\
\text { activity }\end{array}$ & $\begin{array}{c}\text { Only one-third of heparin molecules contain the } \\
\text { high-affinity pentasaccharide required for } \\
\text { anticoagulant activity }\end{array}$ \\
\hline Clearance & $\begin{array}{c}\text { High-molecular-weight moieties are cleared more } \\
\text { rapidly than lower-molecular-weight moieties }\end{array}$ \\
\hline
\end{tabular}




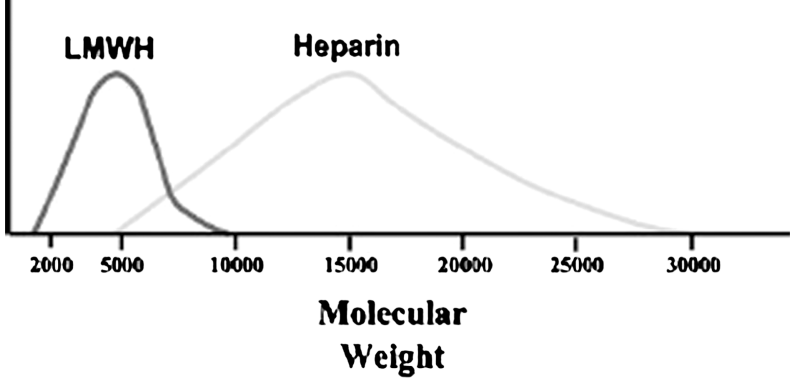

Figure 2. Molecular weight distribution of LMWHs and heparin. LMWH = low-molecular-weight heparin. (Reprinted with permission from $\mathrm{CHEST}^{7}{ }^{\text {) }}$

of HCII requires a higher concentration of heparin than that needed to promote thrombin inhibition by AT. Heparin's capacity to activate HCII is also chain length-dependent, with maximum catalysis requiring heparin chains composed of a minimum of 24 saccharide units. ${ }^{12}$ Consequently, LMWHs are less effective at activating HCII than is heparin.

In vitro, heparin binds to platelets and, depending on the experimental conditions, can either induce or inhibit platelet aggregation. ${ }^{22,23}$ High-molecularweight heparin fractions with low affinity for AT have a greater effect on platelet function than lowmolecular-weight fractions with high AT affinity. ${ }^{24}$ Heparin can prolong the bleeding time in humans, ${ }^{25}$ and it enhances blood loss from the microvasculature in rabbits. ${ }^{20,26,27}$ The interaction of heparin with platelets ${ }^{26}$ and endothelial cells ${ }^{20}$ may contribute to heparin-induced bleeding by mechanisms independent of its anticoagulant effect. ${ }^{27}$

In addition to its anticoagulant effects, heparin attenuates the proliferation of vascular smooth muscle cells, ${ }^{28,29}$ inhibits osteoblast formation, and activates osteoclasts; these last two effects promote bone loss. ${ }^{30,31}$ Heparin-induced thrombocytopenia (HIT) is the most important nonhemorrhagic side effect of heparin. This is discussed by Linkins et $\mathrm{al}^{32}$ in this supplement.

Table 2-Anticoagulant Effects of Heparin

\begin{tabular}{|c|c|}
\hline Effect & Comment \\
\hline $\begin{array}{l}\text { Binds to AT and catalyzes } \\
\text { the inactivation of } \\
\text { thrombin and factors IIa, } \\
\text { Xa, IXa, XIa and XIIa }\end{array}$ & $\begin{array}{l}\text { Major mechanism for anticoagulant } \\
\text { effect, produced by only } \\
\text { one-third of heparin molecules } \\
\text { (those containing the unique } \\
\text { AT-binding pentasaccharide) }\end{array}$ \\
\hline $\begin{array}{l}\text { Binds to HCII and catalyzes } \\
\text { inactivation of factor IIa }\end{array}$ & $\begin{array}{l}\text { Requires high concentrations of } \\
\text { heparin and is independent } \\
\text { of the pentasaccharide }\end{array}$ \\
\hline $\begin{array}{l}\text { Binds to factor IXa and } \\
\text { inhibits factor X Activation }\end{array}$ & $\begin{array}{l}\text { Requires very high concentration } \\
\text { of heparin and is AT- and } \\
\text { HCII-independent }\end{array}$ \\
\hline
\end{tabular}

AT $=$ antithrombin; HCII $=$ heparin cofactor II.
1.1.2 Pharmacokinetics: Heparin is not absorbed orally and therefore must be administered parenterally. The two preferred routes of administration are by continuous IV infusion or subcutaneous injection. When the subcutaneous route is selected for delivery of treatment doses of heparin, the dose of heparin should be higher than the usual IV dose because subcutaneous administration is associated with reduced bioavailability. 33,34 If an immediate anticoagulant effect is required, a higher initial subcutaneous dose of heparin can be administered ${ }^{35}$ Alternatively, an IV bolus of heparin can be given in conjunction with the first subcutaneous dose.

Administration by subcutaneous injection in low $\operatorname{doses}^{36}$ (eg, 5,000 units q12h), moderate doses of 12,500 units $q 12 \mathrm{~h},{ }^{37}$ or 15,000 units $q 12 \mathrm{~h}$ reduces the plasma recovery of heparin. ${ }^{33}$ However, at high therapeutic doses ( $>35,000$ units $q 24 \mathrm{~h}$ ) plasma recovery is almost complete. ${ }^{34}$

After entering the bloodstream, heparin binds to a number of plasma proteins other than AT, reducing its anticoagulant activity. This phenomenon contributes to the variability of the anticoagulant response to heparin among patients with thromboembolic disor$\operatorname{ders}^{38}$ and to the laboratory phenomenon of heparin resistance. ${ }^{39}$ Heparin also binds to endothelial cells ${ }^{40}$ and macrophages, a property that further complicates its pharmacokinetics. Binding of heparin to von Willebrand factor also inhibits von Willebrand factordependent platelet function. ${ }^{41}$

Heparin is cleared through a combination of a rapid saturable and a much slower first-order mechanism (Fig 3). ${ }^{42-44}$ The saturable phase of heparin clearance is believed to be due to binding to endothelial cell receptors ${ }^{45}$ and macrophages. ${ }^{46}$ Bound heparin is internalized and depolymerized (Fig 4).47,48 The slower nonsaturable mechanism of clearance is largely renal. At therapeutic doses, a large proportion of heparin is cleared through the rapid saturable, dose-dependent mechanism. The complex kinetics of clearance render the anticoagulant response to heparin nonlinear at therapeutic doses, with both the intensity and duration of effect rising disproportionately with increasing dose. Thus, the apparent biologic half-life of heparin increases from approximately $30 \mathrm{~min}$ after an IV bolus of 25 units/kg, to $60 \mathrm{~min}$ with an IV bolus of 100 units/kg, to $150 \mathrm{~min}$ with a bolus of 400 units $/ \mathrm{kg}^{42-44}$

1.1.3 Initial Dosing: The efficacy of heparin in the initial treatment of VTE is critically dependent on dosage. Based on the results of randomized studies, ${ }^{33,49}$ patients assigned to lower starting doses of heparin had higher recurrence rates than those treated with higher doses. In the randomized study by Hull and associates, ${ }^{33}$ patients with venous thrombosis were 


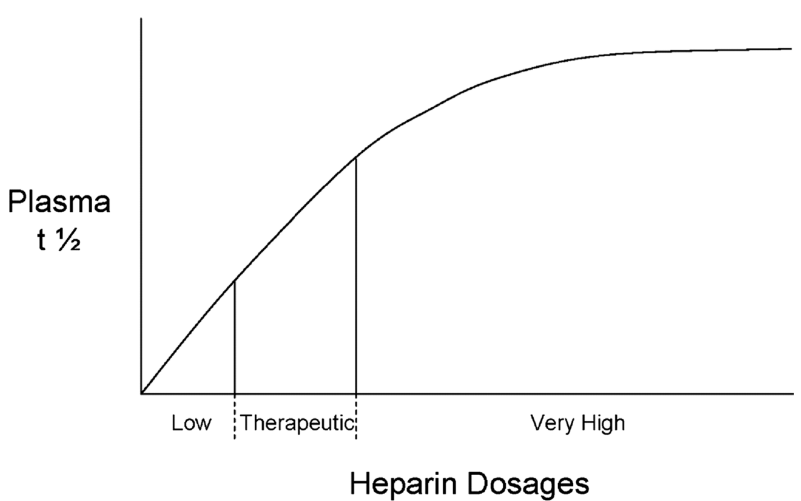

FiguRE 3. Low doses of heparin clear rapidly from plasma through a saturable (cellular) mechanism and the slower, nonsaturable, dose-independent mechanism of renal clearance. Very high doses of heparin are cleared predominantly through the slower nonsaturable mechanism of clearance. $\mathrm{t} 1 / 2=$ half-life. (Reprinted with permission from $\mathrm{CHEST}^{7}{ }^{\text {) }}$

assigned to receive identical doses of heparin (an IV bolus of 5,000 units and 30,000 units per day), but one group received 15,000 units of heparin every $12 \mathrm{~h}$ by subcutaneous injection and the other 30,000 units of heparin per day by continuous IV infusion. Patients assigned to IV heparin had a significantly lower rate of recurrence than those given subcutaneous heparin, presumably as a result of reduced availability of the subcutaneously administered heparin. A study of 400 consecutive patients with acute pulmonary embolism further highlights the importance of early, aggressive therapy: Patients who achieved a therapeutic aPTT in $<24 \mathrm{~h}$ also had lower in-hospital and 30-day mortality rates compared with those who did not. 50

Raschke et $\mathrm{al}^{49}$ randomized patients to receive heparin in fixed doses (5,000-unit bolus followed by 1,000 units/h by infusion) or adjusted doses using a

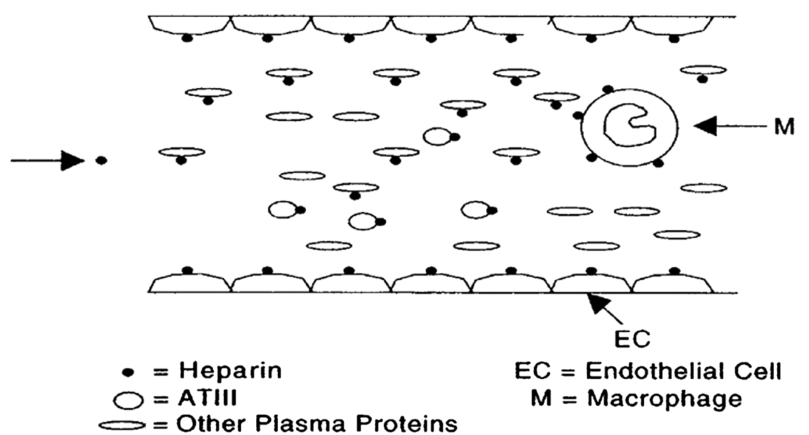

FiguRE 4. As heparin enters the circulation, it binds to heparinbinding proteins (ie, other plasma proteins), endothelial cells, macrophages, and ATIII. Only heparin with the high-affinity pentasaccharide binds to ATIII, but binding to other proteins and to cells is nonspecific and occurs independently of the ATIII binding site. See Figure 1 legend for expansion of abbreviation. (Reprinted with permission from CHEST. ${ }^{7}$ ) weight-based nomogram (starting dose, 80 units $/ \mathrm{kg}$ bolus followed by 18 units/kg/h by infusion). Patients whose heparin was weight-adjusted received higher doses within the first $24 \mathrm{~h}$ than those given fixed doses of heparin. The rate of recurrent thromboembolism was significantly lower with the weightadjusted heparin regimen.

Initial dosing of IV heparin for VTE is either weight-based ( 80 units $/ \mathrm{kg}$ bolus and 18 units $/ \mathrm{kg} / \mathrm{h}$ infusion $^{49}$ ) or administered as a bolus of 5,000 units followed by an infusion of at least 32,000 units/d. ${ }^{51}$ If heparin is given subcutaneously for treatment of VTE, there are at least two options: (1) an initial IV bolus of $\sim 5,000$ units followed by 250 units $/ \mathrm{kg}$ twice daily ${ }^{52}$; or (2) an initial subcutaneous dose of 333 units/kg followed by 250 units/kg twice daily thereafter. ${ }^{35}$

The doses of heparin recommended for treatment of acute coronary syndromes are lower than those used to treat VTE. The American College of Cardiology recommends a heparin bolus of 60 to 70 units $/ \mathrm{kg}$ (maximum 5,000 units) followed by an infusion of 12 to 15 units $/ \mathrm{kg} / \mathrm{h}$ (maximum 1,000 units/h) for unstable angina and non-ST-segment elevation myocardial infarction. ${ }^{53}$ Even lower doses of heparin are recommended when heparin is given in conjunction with fibrinolytic agents for treatment of ST-segment elevation myocardial infarction. Here, the bolus is about 60 units/ $\mathrm{kg}$ (maximum 4,000 units) and the infusion is 12 units $/ \mathrm{kg} / \mathrm{h}$ (maximum of 1,000 units $/ \mathrm{kg} / \mathrm{h}$ ). ${ }^{54}$

1.1.4 Monitoring: The risk of heparin-associated bleeding increases with heparin dose 55,56 and with concomitant administration of fibrinolytic agents ${ }^{57-60}$ or glycoprotein IIb/IIIa inhibitors. ${ }^{61,62}$ The risk of bleeding is also increased by recent surgery, trauma, invasive procedures, or concomitant hemostatic defects. ${ }^{63}$ In hospitalized patients, increasing number of comorbidities, age $>60 \mathrm{y}$, supratherapeutic clotting times, and worsening hepatic dysfunction increase the risk of anticoagulant-associated bleeding. ${ }^{64}$

Investigators have reported a relationship between the dose of heparin administered and both its efficacy $^{33,47,65}$ and safety. ${ }^{61,62}$ Because the anticoagulant response to heparin varies among patients, it is standard practice to monitor heparin and to adjust the dose based on the results of coagulation tests. The evidence for adjusting the dose of heparin to maintain a "therapeutic range" is weak and is based on a post hoc subgroup analysis of a descriptive study. ${ }^{66} \mathrm{In}$ contrast, the evidence for maintaining the international normalized ratio (INR) within a "therapeutic range" in patients who are treated with vitamin $\mathrm{K}$ antagonists is strong because it is based on consistent results of randomized trials and case control studies. 
When given in therapeutic doses, the anticoagulant effect of heparin is usually monitored using the aPTT. The activated clotting time is used to monitor the higher heparin doses given to patients undergoing percutaneous coronary interventions or cardiopulmonary bypass surgery.

A retrospective study done in the 1970s suggested that an aPTT ratio between 1.5 and 2.5 was associated with a reduced risk of recurrent VTE. ${ }^{66}$ Based on this study, a therapeutic aPTT range of 1.5 to 2.5 times control gained wide acceptance. The clinical relevance of this therapeutic range is uncertain because it has not been confirmed by randomized trials. Further, the measured response to the aPTT varies between reagents and instruments used to measure the aPTT. ${ }^{67-76}$ Depending on reagent and coagulometer, aPTT results ranging from 48 to $108 \mathrm{~s}$ can be measured in samples with a heparin concentration of 0.3 units $/ \mathrm{mL}$, as determined using an anti-Xa assay. ${ }^{69,71}$ With heparin levels of 0.3 to 0.7 anti-Xa units $/ \mathrm{mL}$, modern aPTT reagents and coagulometers produce aPTT ratios that range from 1.6-2.7 to 3.7-6.2 times control. ${ }^{67-72,74-81}$ Although various heparin dose-adjustment nomograms have been developed (Table 365), none is applicable to all aPTT reagents. ${ }^{71}$ For these reasons, the therapeutic aPTT range at a particular institution should be adapted to the responsiveness of the reagent and coagulometer used. ${ }^{67,70,72,73,75,76,78,80-83}$ In the study that established a therapeutic range for the aPTT, ${ }^{66}$ an aPTT ratio of 1.5 to 2.5 corresponded to a heparin level of 0.2 to 0.4 units by protamine titration and a heparin level of 0.3 to 0.7 units measured by an anti-Xa assay. Like aPTT assays, anti-Xa assays vary in their responsiveness to heparin; therefore, standardization of aPTT ratios by reference to anti-Xa levels is also problematic. Studies evaluating interlaboratory agreement in the monitoring of heparin have failed to show that correlating the aPTT with anti-Xa assays improves agreement between hospital laboratories $, 84,85$ reflecting, at

Table 3-Example of a Heparin Dose Adjustment Nomogram

\begin{tabular}{ll}
\hline \hline Initial dose & 80 units $/ \mathrm{kg}$ bolus, then 18 units $/ \mathrm{kg} / \mathrm{h}$ \\
\hline aPTT, $<35 \mathrm{~s}$ & 80 units $/ \mathrm{kg}$ bolus, then increase $4 \mathrm{units} / \mathrm{kg} / \mathrm{h}$ \\
\hline aPTT, $35-45 \mathrm{~s}$ & 40 units $/ \mathrm{kg}$ bolus, then increase 2 units $/ \mathrm{kg} / \mathrm{h}$ \\
\hline aPTT, $46-70 \mathrm{~s}^{\mathrm{a}}$ & No change \\
\hline aPTT, $71-90 \mathrm{~s}$ & Decrease infusion rate by 2 units $/ \mathrm{kg} / \mathrm{h}$ \\
\hline aPTT, $>90 \mathrm{~s}$ & $\begin{array}{c}\text { Hold infusion } 1 \mathrm{~h}, \text { then decrease infusion } \\
\text { rate by } 3 \text { units } / \mathrm{kg} / \mathrm{h}\end{array}$ \\
\hline
\end{tabular}

aPTT $=$ activated partial thromboplastin time. (Adapted with permission from Raschke et al. ${ }^{65}$ )

aTherapeutic aPTT range of 46-70 s corresponded to anti-Xa activity of 0.3-0.7 units $/ \mathrm{mL}$. The target aPTT range in a particular institution should reflect what is known about the local reagents and equipment used to perform the assay. least in part, greater variation in the results of anti-Xa assays than in the aPTT results. ${ }^{84}$ Therefore, more research is needed to identify the optimal approach for monitoring unfractionated heparin (UFH) therapy. The therapeutic range of heparin for coronary indications is unknown, but is likely to correspond to heparin levels that are about 10\% lower than those used for treatment of patients with VTE. The results of a randomized trial in patients with VTE that showed that unmonitored weight-adjusted subcutaneous heparin given twice daily in high doses was as safe and effective as unmonitored, weight-adjusted LMWH challenge the requirement for aPTT monitoring of heparin administered subcutaneously. ${ }^{35}$

1.1.5 Heparin Resistance: Heparin resistance is a term used to describe the situation wherein patients require unusually high doses of heparin to achieve a therapeutic aPTT. ${ }^{86-88}$ Several mechanisms explain heparin resistance, including AT deficiency, ${ }^{73}$ increased heparin clearance, ${ }^{38,87}$ elevations in the levels of heparin-binding proteins, ${ }^{39,89}$ and high levels of factor VIII ${ }^{88,90}$ and/or fibrinogen. ${ }^{90}$ Aprotinin and nitroglycerin may cause drug-induced heparin resistance,,$_{1,92}$ although the association with nitroglycerin is controversial. ${ }^{82}$

In patients with VTE who required large doses of heparin $(>35,000$ units/d), patients randomized to heparin dosing based on anti-Xa levels (target range between $0.35-0.7$ units $/ \mathrm{mL}$ ) had similar clinical outcomes and received lower doses of heparin than those randomized to dose adjustment based on aPTT values. ${ }^{88}$ Given these results, it is reasonable to adjust heparin doses based on anti-Xa levels in patients with VTE who require very high doses of heparin to achieve a therapeutic aPTT.

1.1.6 Limitations of Heparin: In addition to hemorrhagic complications, heparin has limitations based on its pharmacokinetic properties; its ability to induce immune-mediated platelet activation, which can lead to HIT $^{32}$; and its effect on bone metabolism, which can lead to osteoporosis. Other nonhemorrhagic side effects are very uncommon and include skin reactions that can progress to necrosis, alopecia, and hypersensitivity reactions..$^{93}$ Although hypersensitivity reactions to heparin are uncommon, an unusually high number of adverse events with heparin were reported in North America in 2007. Typically, these events consisted of hypotension, nausea, and shortness of breath within $30 \mathrm{~min}$ of heparin administration. An investigation into this problem conducted by the US Centers for Disease Control identified the cause of these reactions to be a contaminant in heparin manufactured in China. The contaminant was an oversulfated chondroitin sulfate. ${ }^{94}$ It is postulated that 
oversulfated chondroitin sulfate induces hypotension by promoting the activation of factor XII and the subsequent generation of bradykinin. ${ }^{95}$

Heparin therapy can also cause elevations of serum transaminases. The increase in transaminases is usually transient and is not associated with an increase in bilirubin; it is presumed to have no clinical consequences. ${ }^{96}$

The main nonhemorrhagic side effects of heparin are HIT and osteoporosis. HIT (discussed further by Linkins et $\mathrm{al}^{32}$ in this supplement) is caused by $\operatorname{IgG}$ subclass, heparin-dependent antibodies. These antibodies bind to a conformationally modified epitope on platelet factor 4 (PF4). Simultaneous binding of these antibodies to $\mathrm{Fc}$ receptors on the platelet surface causes platelet activation. Activated platelets shed highly prothrombotic microparticles and are then removed from the circulation causing thrombocytopenia. In addition, these activated platelets and microparticles provide a surface onto which coagulation factor complexes can assemble to promote thrombin generation. This phenomenon can then trigger venous or arterial thrombosis with venous thrombosis being more common. ${ }^{97}$ Osteoporosis is caused by binding of heparin to osteoblasts, ${ }^{32}$ which then release factors that activate osteoclasts in an interleukin 11-dependent fashion. ${ }^{98}$

\subsubsection{Reversing the Anticoagulant Effect of Heparin:} One advantage of heparin is that IV protamine sulfate can rapidly reverse its anticoagulant effects. Protamine sulfate is a basic protein derived from fish sperm that binds to heparin to form a stable salt. One milligram of protamine sulfate will neutralize approximately 100 units of heparin. Therefore, a patient who bleeds immediately after receiving an IV bolus of 5,000 units of heparin should receive about $50 \mathrm{mg}$ of protamine sulfate. Protamine sulfate is cleared from the circulation with a half-life of about $7 \mathrm{~min}$. Because the half-life of IV heparin is 60 to $90 \mathrm{~min}$ when heparin is given as an IV infusion, only heparin given during the preceding several hours needs to be considered when calculating the dose of protamine sulfate that needs to be administered. Therefore, a patient receiving a continuous IV infusion of heparin at 1,250 units/h requires approximately $30 \mathrm{mg}$ of protamine sulfate to neutralize the heparin that was given in the past 2 to $2.5 \mathrm{~h}$. Neutralization of subcutaneously administered heparin may require a prolonged infusion of protamine sulfate. The aPTT can be used to assess the effectiveness of protamine sulfate neutralization of the anticoagulant effects of heparin. ${ }^{99}$

The risk of severe adverse reactions to protamine sulfate, such as hypotension or bradycardia, can be minimized by administering the protamine slowly.
Patients who have previously received protamine sulfate-containing insulin, have undergone vasectomy, or have known sensitivity to fish are at increased risk to have preformed antibodies against protamine sulfate and to suffer from allergic reactions, including anaphylaxis. ${ }^{100,101}$ Such reactions are uncommon, but if there is concern about a potential protamine sulfate allergy, patients can be pretreated with corticosteroids and antihistamines.

A number of other substances or devices have been shown to neutralize the anticoagulant effects of UFH. These include hexadimethrine (Polybrene), ${ }^{102,103}$ heparinase (Neutralase), ${ }^{104} \mathrm{PF} 4,{ }^{105,106}$ extracorporeal heparin removal devices, ${ }^{107}$ and synthetic protamine variants. ${ }^{108}$ None of these is approved for clinical use.

\subsection{Low-Molecular-Weight Heparins}

LMWHs are derived from UFH by chemical or enzymatic depolymerization. LMWHs have reduced inhibitory activity against thrombin relative to factor $\mathrm{Xa},{ }^{9,10,109-111}$ have a more favorable benefit-to-risk ratio than heparin in animal models ${ }^{112,113}$ and when used to treat VTE, 114 and have superior pharmacokinetic properties. ${ }^{115-121}$

\subsubsection{Structure and Mechanism of Action: LMWHs} are about one-third the molecular weight of UFH. LMWHs have a mean molecular weight of 4,000 to 5,000 — which corresponds to about 15 saccharide units - and a range of 2,000 to 9,000. Table 4 shows the various LMWHs approved for use in Europe, Canada, and the United States. Because they are prepared using different methods of depolymerization, the various LMWHs differ, at least to some extent, in their pharmacokinetic properties and anticoagulant profiles and in their recommended dosing regimens. Therefore, these drugs are not interchangeable on a unit-for-unit basis.

Table 4-Methods for Preparation of LMWH and Danaparoid

\begin{tabular}{lc}
\hline \hline Agent & Method of Preparation \\
\hline Bemiparin & Alkaline degradation \\
\hline Dalteparin (Fragmin) & Nitrous acid depolymerization \\
\hline $\begin{array}{c}\text { Danaparoid sodium } \\
\text { (Orgaran) }\end{array}$ & $\begin{array}{c}\text { Prepared from animal gut mucosa; contains } \\
\text { heparan sulfate (84\%), dermatan sulfate } \\
(12 \%) \text {, and chondroitin sulfate }(4 \%)\end{array}$ \\
\hline $\begin{array}{c}\text { Enoxaparin sodium } \\
\text { (Lovenox/Clexane) }\end{array}$ & $\begin{array}{c}\text { Benzylation followed by alkaline } \\
\text { depolymerization }\end{array}$ \\
\hline $\begin{array}{c}\text { Nadroparin calcium } \\
\text { (Fraxiparine) }\end{array}$ & $\begin{array}{c}\text { Nitrous acid depolymerization } \\
\text { Tinzaparin (Innohep) }\end{array}$ \\
\end{tabular}

LMWH $=$ low-molecular-weight heparin. 
Table 5-Biologic Consequences of Reduced Binding of LMWH to Plasma Proteins and Cells

\begin{tabular}{|c|c|c|}
\hline Binding Target & Biologic Effects & Clinical Consequence \\
\hline Thrombin & $\begin{array}{l}\text { Reduced anti-IIa activity } \\
\text { relative to anti-Xa activity }\end{array}$ & Unknown \\
\hline Proteins & $\begin{array}{l}\text { More predictable } \\
\text { anticoagulant response }\end{array}$ & $\begin{array}{l}\text { Coagulation monitoring } \\
\text { unnecessary }\end{array}$ \\
\hline Macrophages & $\begin{array}{l}\text { Cleared through renal } \\
\text { mechanism }\end{array}$ & $\begin{array}{l}\text { Longer plasma half-life } \\
\text { permits once-daily } \\
\text { administration }\end{array}$ \\
\hline $\begin{array}{l}\text { Platelets } \\
\text { and PF4 } \\
\end{array}$ & $\begin{array}{l}\text { Reduced formation of } \\
\text { HIT antibodies }\end{array}$ & $\begin{array}{l}\text { Reduced incidence } \\
\text { of HIT }\end{array}$ \\
\hline Osteoblasts & $\begin{array}{l}\text { Reduced activation of } \\
\text { osteoclasts }\end{array}$ & $\begin{array}{r}\text { Lower risk of } \\
\text { osteopenia }\end{array}$ \\
\hline
\end{tabular}

$\mathrm{HIT}=$ heparin-induced thrombocytopenia. See Table 4 legend for expansion of other abbreviation.

Depolymerization of heparin yields low-molecular weight fragments that exhibit reduced binding to proteins and cells (Table 5). The reduced affinity for proteins and cells explains the anticoagulant, pharmacokinetic, and other biologic differences between heparin and LMWH. Thus, compared with heparin, LMWHs have reduced ability to inactivate thrombin because the smaller fragments cannot bind simultaneously to AT and thrombin. Reduced binding to plasma proteins other than AT is responsible for the more predictable dose-response relationship of LMWHs. ${ }^{122}$ Decreased binding to macrophages and endothelial cells explains the longer plasma half-life of LMWH relative to UFH, whereas reduced binding to platelets and $\mathrm{PF} 4$ explains the lower incidence of HIT. ${ }^{123,124}$ Finally, the decreased binding of LMWH to osteoblasts results in less activation of osteoclasts and less bone loss. ${ }^{30,31}$

Like heparin, LMWHs produce their major anticoagulant effect by catalyzing AT-mediated inhibition of coagulation factors. The pentasaccharide sequence required for binding is found on fewer than one-third of LMWH molecules. ${ }^{14,125}$ Because only pentasaccharide-containing heparin chains composed of at least 18 saccharide units are of sufficient length to bridge AT to thrombin, $50 \%$ to $75 \%$ of $\mathrm{LMWH}$ chains are too short to catalyze thrombin inhibition. However, these chains are capable of promoting factor Xa inactivation by AT because this reaction does not require bridging. Because virtually all molecules of UFH contain at least 18 saccharide units, heparin has, by definition, an anti-Xa to anti-IIa ratio of 1:1. In contrast, commercial LMWHs have anti-Xa to anti-IIa ratios between 2:1 and 4:1 depending on their molecular size distribution. At present, there is no evidence that the differences in anti-Xa to anti-IIa ratio among the LMWHs influence clinical outcomes such as recurrent thrombosis or bleeding complications. Numerous randomized clinical trials have shown that LMWHs are safe and effective for the prevention and treatment of VTE and for the treatment of non-ST-elevation acute coronary syndromes.

1.2.2 Pharmacokinetics: LMWHs have pharmacokinetic advantages over heparin; ${ }^{115,116,121}$ after subcutaneous injection, the bioavailability of LMWHs is about $90 \%$ and LMWHs produce a more predictable anticoagulant response than heparin. ${ }^{126}$ The elimination half-life of LMWHs, which is 3 to $6 \mathrm{~h}$ after subcutaneous injection, is dose independent, and anti-Xa levels peak 3 to $5 \mathrm{~h}$ after dosing. One limitation of LMWHs is that they are predominately cleared by the kidneys so their biologic half-life may be prolonged in patients with renal failure. ${ }^{127,128}$

\subsubsection{Monitoring Antithrombotic Effect: LMWHs} are typically administered in fixed or weight-adjusted doses for thromboprophylaxis and in weight-adjusted doses for therapeutic purposes. Coagulation monitoring is not generally necessary, but some authorities suggest that monitoring be done in obese patients and in those with renal insufficiency. ${ }^{129-131}$ Monitoring may also be advisable when treatment doses of LMWH are given during pregnancy. ${ }^{132}$

Although some studies reported that high anti-Xa levels were associated with an increased bleeding risk, ${ }^{55,133}$ several other studies failed to show a relationship between anti-Xa levels and bleeding. ${ }^{134-136}$ A randomized controlled trial comparing monitored and unmonitored dalteparin therapy for treatment of VTE showed no benefit of monitoring. ${ }^{137}$ Monitoring is thus not recommended for the majority of patients; if monitoring is required, the anti-Xa level is the recommended test. ${ }^{138}$

For treatment of VTE, a conservative peak anti-Xa level with twice-daily enoxaparin or nadroparin is 0.6 to 1.0 units $/ \mathrm{mL} .{ }^{132,138-140}$ The target range for peak anti-Xa levels (measured $4 \mathrm{~h}$ after dosing) with oncedaily enoxaparin is likely to be above 1.0 units $/ \mathrm{mL},{ }^{138}$ whereas it is 0.85 units $/ \mathrm{mL}$ with tinzaparin and 1.3 units $/ \mathrm{mL}$ and 1.05 units $/ \mathrm{mL}$ with nadroparin and dalteparin, respectively. ${ }^{140}$ The suggested peak target ranges for several LMWHs are shown in Table 6.

\subsubsection{Dosing and Monitoring in Special Situations:} With enoxaparin, anti-Xa activity is increased to appropriate levels when the drug is administered to obese patients in doses based on total body weight up to a weight of $144 \mathrm{~kg}$. ${ }^{141}$ The same is true for dalteparin ${ }^{142,143}$ and tinzaparin ${ }^{144}$ in patients weighing up to 190 and $165 \mathrm{~kg}$, respectively. In a meta-analysis that included data on 921 patients with a $\mathrm{BMI} \geq 30$, there was no excess in the rate of major bleeding over that observed in nonobese patients who received 
Table 6-LMWH Target Ranges for the Treatment of VTE

LMWH and Frequency

of Administration

Target Range ${ }^{\mathrm{a}}$ (Anti-Xa units/mL)

\begin{tabular}{lc}
\hline Twice daily enoxaparin & $0.6-1.0$ \\
\hline Twice daily nadroparin & $0.6-1.0$ \\
\hline Once daily dalteparin & 1.05 \\
\hline Once daily enoxaparin & $>1.0$ \\
\hline Once daily nadroparin & 1.3 \\
\hline Once daily tinzaparin & 0.85
\end{tabular}

See Table 4 legend for expansion of abbreviation.

${ }^{a}$ Measured $4 \mathrm{~h}$ after LMWH administration.

LMWH in doses adjusted by total body weight. ${ }^{145}$ For thromboprophylaxis with fixed-dose enoxaparin and nadroparin, there is a strong negative correlation between total body weight and anti-Xa levels in obese patients. ${ }^{146-148}$ Several small prospective trials have examined this issue in patients undergoing bariatric surgery, with inconclusive findings. ${ }^{149-152}$

Appropriate dosing of LMWH in patients with severe renal insufficiency is uncertain. Contemporary randomized controlled trials evaluating LMWH efficacy and safety have generally excluded patients with severe renal insufficiency, defined in most studies as a creatinine clearance $(\mathrm{CrCl}) \leq 30 \mathrm{~mL} / \mathrm{min}$. With few exceptions, ${ }^{153}$ pharmacokinetic studies have demonstrated that clearance of the anti-Xa effect of LMWH is highly correlated with $\mathrm{CrCl} .{ }^{154}$ This was also observed in a large study of patients receiving therapeutic-dose enoxaparin for coronary indications, in which a strong linear relationship was reported between $\mathrm{CrCl}$ and enoxaparin clearance $(R=0.85$, $P<.001) .{ }^{141}$ Of particular concern is the potential for accumulation of anti-Xa activity after multiple therapeutic doses. A linear correlation was shown between $\mathrm{CrCl}$ and anti-Xa levels $(P<.0005)$ after multiple therapeutic doses of enoxaparin, with significantly increased anti-Xa levels in patients with a $\mathrm{CrCl}<30 \mathrm{~mL} / \mathrm{min} .{ }^{155}$ Accumulation after multiple prophylactic doses appears to occur less frequently, but it is still observed. Thus, after multiple prophylactic doses of enoxaparin, anti-Xa clearance was reduced by $39 \%$ and drug exposure (area under the curve of anti-Xa activity vs time) was $35 \%$ higher in patients with a $\mathrm{CrCl}<30 \mathrm{~mL} / \mathrm{min}$ compared with that in patients with a $\mathrm{CrCl} \geq 30 \mathrm{~mL} / \mathrm{min} .{ }^{156}$ The data on accumulation with LMWHs other than enoxaparin is limited. Although the amount of published evidence is limited, bioaccumulation of dalteparin has been reported in patients with significant renal insufficiency who receive therapeutic doses of dalteparin. ${ }^{157}$ When used in full therapeutic doses, nadroparin clearance, but not tinzaparin clearance, was shown to be correlated with $\mathrm{CrCl}$ $(\mathrm{R}=0.49, P<.002),{ }^{158}$ even when the $\mathrm{CrCl}$ was as low as $20 \mathrm{~mL} / \mathrm{min} .{ }^{159}$ The apparent difference in tinzaparin clearance in patients with severe renal insufficiency may reflect metabolism by hepatic mechanisms, possibly due to the higher molecular weight of tinzaparin compared with other LMWHs.

Decreased LMWH clearance has been associated with increased bleeding risks in patients with severe renal insufficiency. Lim and associates ${ }^{160}$ compared the risk of major bleeding and anti-Xa levels in patients receiving LMWH who had severe renal insufficiency $(\mathrm{CrCl} \leq 30 \mathrm{~mL} / \mathrm{min})$ with those in patients without renal impairment $(\mathrm{CrCl}>30 \mathrm{~mL} / \mathrm{min})$. In 12 studies involving 4,971 patients given LMWH, the OR for major bleeding was 2.25 (95\% CI, 1.19-4.27) in patients with a $\mathrm{CrCl} \leq 30 \mathrm{~mL} / \mathrm{min}$ compared with that in those with a $\mathrm{CrCl}>30 \mathrm{~mL} / \mathrm{min}$. Enoxaparin at a therapeutic dose was associated with a further increase in major bleeding in patients with a $\mathrm{CrCl} \leq 30 \mathrm{~mL} / \mathrm{min}(8.3 \%$ vs $2.4 \%$; OR, 3.88 ; $95 \%$ CI, 1.78-8.45), but this was not observed when enoxaparin was empirically dose reduced $(0.9 \%$ vs 1.9\%; OR, 0.58; 95\% CI, 0.09-3.78). Based on these data, nondialysis-dependent patients with $\mathrm{CrCl} \leq 30 \mathrm{~mL} / \mathrm{min}$ who are treated with standard therapeutic doses of enoxaparin have an increased risk of major bleeding, and empirical dose reduction appears to reduce this risk. No conclusions could be made regarding other LMWHs because of limited data.

Increased bleeding was also found in a post hoc analysis of data from the Efficacy and Safety of Subcutaneous Enoxaparin in Non-Q-Wave Coronary Events (ESSENCE) and Thrombolysis in Myocardial Infarction (TIMI) 11B trials, in which $\mathrm{CrCl} \leq 30 \mathrm{~mL} / \mathrm{min}$ was associated with an increased risk for major hemorrhage in patients receiving therapeutic doses of enoxaparin (relative risk $[\mathrm{RR}]=6.1$; 95\% CI, 2.47-14.88; $P=.0019) .{ }^{161}$ In another study in patients with either VTE or acute coronary ischemia treated with therapeutic doses of enoxaparin or tinzaparin, a $\mathrm{CrCl}<20 \mathrm{~mL} / \mathrm{min}$ was associated with a RR of 2.8 (95\% CI, 1.0-7.8) for bleeding complications. ${ }^{162}$ Finally, in a retrospective study of patients receiving multiple doses of enoxaparin, patients with renal insufficiency had an RR for any bleeding complication of $2.3(P<.01)$ and an RR for major hemorrhage of $15.0(P<.001) .163$

In the setting of severe renal insufficiency in which therapeutic anticoagulation is required, use of UFH avoids the problems associated with impaired clearance of LMWH preparations. Although there is no specific $\mathrm{CrCl}$ threshold at which the risk for LMWH accumulation becomes clinically significant, an estimated $\mathrm{CrCl}$ of about $30 \mathrm{~mL} / \mathrm{min}$ is a reasonable cutoff value based on the available literature. If LMWH is chosen for patients with an estimated creatinine clearance of $<30 \mathrm{~mL} / \mathrm{min}$, anti-Xa monitoring 
and/or dose reduction should be considered to ensure that there is no accumulation. In the case of enoxaparin, dose reduction may be used in patients with $\mathrm{CrCl}<30 \mathrm{~mL} / \mathrm{min}$. The recommended treatment dose of enoxaparin for patients with a $\mathrm{CrCl}<30 \mathrm{~mL} / \mathrm{min}$ who have acute coronary syndromes or VTE is $50 \%$ of the usual dose (ie, $1 \mathrm{mg} / \mathrm{kg}$ once daily). No specific recommendations have been made for other LMWH preparations.

When given in prophylactic doses, LMWH has not been shown to increase the risk of bleeding complications, irrespective of the degree of impairment of renal function. Although higher anti-Xa levels were found in patients with renal failure who received repeated once-daily prophylactic doses of enoxaparin, the mean peak anti-Xa level was only 0.6 units $/ \mathrm{mL}$, the trough was $<0.2$ units $/ \mathrm{mL}$, and no increased bleeding was observed. ${ }^{156,164}$ In a prospective cohort study of critically ill patients with a wide range of renal function, including some with acute renal failure who required hemodialysis, dalteparin bioaccumulation was not observed despite repeated dosing. ${ }^{165}$ In a more recent study, subcutaneous dalteparin (5,000 International Units) was given daily to consecutive ICU patients who had an estimated creatinine clearance $<30 \mathrm{~mL} / \mathrm{min}$. There was no evidence of drug accumulation nor was the risk of bleeding increased. ${ }^{166}$ For patients with a $\mathrm{CrCl}<30 \mathrm{~mL} / \mathrm{min}$ who require pharmacologic VTE prophylaxis, manufacturer of enoxaparin recommends that $30 \mathrm{mg}$ once daily be used. In a small comparative study of enoxaparin (40 mg once daily) or tinzaparin (4,500 units once daily), bioaccumulation of enoxaparin, but not tinzaparin, was seen over 8 days of exposure. ${ }^{167}$ For other LMWHs, dosing recommendations cannot be made in the setting of renal insufficiency.

\subsubsection{Reversing the Anticoagulant Effects of} LMWH: There is no proven method for neutralizing LMWH. Studies in vitro and in animals have demonstrated that protamine sulfate neutralizes the anti-IIa activity of LMWH, thereby normalizing the aPTT and the thrombin time. However, protamine sulfate neutralizes a variable portion of the anti-Xa activity of LMWH. ${ }^{168-172}$ It is likely that incomplete neutralization of anti-Xa activity reflects the fact that protamine does not bind to LMWH fragments within the LMWH preparations that have low sulfate charge density. ${ }^{173,174}$

The clinical significance of incomplete anti-Xa neutralization of LMWH by protamine sulfate is unclear. In a small case series, protamine sulfate failed to correct clinical bleeding associated with LMWH in two of three patients, ${ }^{169}$ but there are no human studies that convincingly demonstrate or refute a beneficial effect of protamine sulfate on bleeding associated with the use of LMWH. One animal study reported a reduction in bleeding with protamine sulfate in a microvascular bleeding model, despite persistent anti-Xa activity. ${ }^{175}$ Another study demonstrated incomplete attenuation of LMWHinduced bleeding. ${ }^{176}$

A single case report describes the successful use of recombinant activated factor VII to control bleeding in a postoperative patient with renal failure who was receiving LMWH. ${ }^{177}$ In animal studies, synthetic protamine variants have been shown to be highly effective in neutralizing the anticoagulant effects of LMWH (including anti-Xa activity) and appear to be less toxic than protamine sulfate. ${ }^{109,178-180}$ Adenosine triphosphate completely reversed LMWH-induced bleeding related to $\mathrm{LMWH}$ in a rat model, ${ }^{181}$ as did PMX 60056, a salicylamide-derived heparin antagonist. ${ }^{182}$ In vitro experiments suggest that an antithrombin variant (AT-N135Q-Pro394) may neutralize the anticoagulant effects of heparin derivatives, including LMWH and fondaparinux. These agents are not approved for clinical use.

The following approach is recommended in clinical situations in which the anticoagulant effect of LMWH needs to be neutralized. If LMWH was given within $8 \mathrm{~h}$, protamine sulfate should be administered in a dose of $1 \mathrm{mg}$ per 100 anti-Xa units of LMWH up to a maximum single dose of $50 \mathrm{mg}$ ( $1 \mathrm{mg}$ enoxaparin equals approximately 100 anti-Xa units). A second dose of $0.5 \mathrm{mg}$ protamine sulfate per 100 anti-Xa units should be administered if bleeding continues. Smaller doses of protamine sulfate can be given if the time since LMWH administration is longer than $8 \mathrm{~h}$.

1.2.6 Nonhemorrhagic Complications: The frequency of HIT is threefold lower with LMWHs than with heparin. ${ }^{124}$ This reflects the fact that the interaction of heparin with PF4 is chain length-dependent. Although binding to PF4 is reduced, LMWHs can form complexes with PF4 that are capable of binding HIT antibodies. Consequently, in patients with HIT antibodies, there is cross-reactivity with LMWH (Linkins et al). ${ }^{32}$

The risk of osteoporosis is lower with LMWH than with heparin. Likely, this reflects the lower affinity of LMWH for osteoclasts and osteoblasts. Monreal and associates $^{183}$ compared the effects of heparin and LMWH on bone loss in rats and demonstrated that although both produced bone loss, the osteopenic effect was greater with heparin than LMWH. In contrast, using different measures of bone loss, Mätzsch and associates ${ }^{184}$ reported that, at similar anti-factor Xa activities, the effects of LMWH and UFH on experimental bone loss were similar. Shaughnessy and colleagues reported that heparin and LMWH both 
produced a dose-dependent decrease in cancellous bone volume in rats. However, the effects were greater with UFH than with LMWH. ${ }^{185}$ These investigators also showed that although both anticoagulants inhibited bone nodule formation and increased alkaline phosphatase in a dose-dependent manner, UFH had a sixfold greater effect than LMWH. ${ }^{30}$ Other investigators also reported that LMWH causes significant inhibition of osteoblast growth ${ }^{186}$ and produces osteopenic changes in rats. ${ }^{187}$

Three small prospective clinical studies have reported on the effects of prophylactic doses of LMWH on bone density. The first was a cohort study in which 16 women receiving enoxaparin $(40 \mathrm{mg}$ daily) during pregnancy had serial bone density measurements of the proximal femur. Baseline measurements were taken within 2 weeks of starting therapy and then at 6 to 8 weeks and 6 months postpartum. Patients received enoxaparin for a mean duration of 25 weeks (range, 19-32 weeks). Compared with baseline values, there was no significant change in mean bone density at 6 weeks postpartum and no patient experienced $a>10 \%$ decrease in bone mass. At 6 months postpartum, there was a significant reduction in mean bone density $(P=.02)$ and two of the 14 patients evaluated (14\%) had a $>10 \%$ decrease. ${ }^{188}$

The second study was an open randomized trial that included 44 pregnant women with VTE. Patients were assigned to either prophylactic doses of LMWH (dalteparin; $\mathrm{n}=21$ ) once daily subcutaneously or UFH $(\mathrm{n}=23)$ twice daily subcutaneously during pregnancy and the puerperium. Dual $\mathrm{x}$-ray absorptiometry of the lumbosacral spine was performed at $1,6,16$, and 52 weeks. A healthy untreated control group was included for comparison. Mean bone density of the lumbar spine was significantly lower in the UFH group than in the dalteparin or control groups. Bone density measurements did not differ between the dalteparin and control groups. ${ }^{189}$

The third clinical trial compared the effects of long-term treatment with LMWH (enoxaparin) and acenocoumarol on bone mineral density in 86 patients with VTE. Treatment was given for 3 to 24 months. At 1 and 2 years of follow-up, the mean decrease in bone density of the femur was $1.8 \%$ and $2.6 \%$ in patients given acenocoumarol and $3.1 \%$ and $4.8 \%$ in patients given enoxaparin, respectively. These differences were not statistically significant. ${ }^{190}$ A recent review confirms that the strength of the association between LMWH and osteoporosis remains unclear. ${ }^{191}$

In summary, both UFH and LMWH preparations have the potential to produce osteopenia. The risk is lower with LMWH.

\subsection{Fondaparinux}

1.3.1 Discovery of the Natural High-Affinity Pentasaccharide: Building on the discovery of Lindahl and associates, who isolated heparin fragments with high affinity for AT, Choay and colleagues ${ }^{192}$ and Thunberg et al ${ }^{193}$ demonstrated that the minimum heparin fragment necessary for high-affinity binding to AT consisted of a pentasaccharide. Choay and associates ${ }^{125,194}$ then isolated this high-affinity pentasaccharide and demonstrated that it formed an equimolar complex with AT and enhanced ATmediated inhibition of factor Xa. In 1987, Atha and associates $^{195}$ reported that both the 3-O- and 6-Osulfated glucosamine residues within the pentasaccharide sequence were critical for its activity. These observations paved the way for the development of fondaparinux.

1.3.2 Pharmacology: A synthetic analog of the AT-binding pentasaccharide found in heparin and LMWH was prepared and its structure modified so as to increase its affinity for AT, thereby increasing its specific activity and its half-life. The resulting synthetic pentasaccharide, fondaparinux, has a molecular weight of 1,728 . Its specific anti-Xa activity is higher than that of LMWH (about 700 units/mg and $100 \mathrm{units} / \mathrm{mg}$, respectively), and its half-life after subcutaneous injection is longer than that of LMWH ( $17 \mathrm{~h}$ and about $4 \mathrm{~h}$, respectively). The use of LMWH as the reference preparation for determining the measured anti-Xa activity of fondaparinux is problematic. ${ }^{196,197}$ As a result, fondaparinux levels should only be determined using assays that use known fondaparinux concentrations to generate their standard curve.

Fondaparinux binds to AT and produces a conformational change at the reactive site of AT that enhances its reactivity with factor Xa. ${ }^{198}$ AT then forms a covalent complex with factor Xa. Fondaparinux is released from AT and is available to activate additional AT molecules. Because it is too short to bridge AT to thrombin, fondaparinux does not increase the rate of thrombin inhibition by AT.

The pharmacokinetic properties and metabolism of fondaparinux have been studied in healthy volunteers. ${ }^{199,200}$ After subcutaneous injection, fondaparinux is rapidly and completely absorbed. A steady state is reached after the third or fourth once-daily dose, and fondaparinux is excreted unchanged in the urine. The terminal half-life is $17 \mathrm{~h}$ in young subjects and $21 \mathrm{~h}$ in elderly volunteers. Fondaparinux produces a predictable anticoagulant response and exhibits linear pharmacokinetics when given in subcutaneous doses of 2 to $8 \mathrm{mg}$ or in IV doses ranging from 2 to $20 \mathrm{mg}$. ${ }^{200}$ There is minimal nonspecific binding of fondaparinux 
to plasma proteins other than AT, and most of the compound is bound to AT. ${ }^{201}$

Based on its almost complete bioavailability after subcutaneous injection, lack of variability in anticoagulant response, and long half-life, fondaparinux can be administered subcutaneously once daily in fixed doses without coagulation monitoring. Fondaparinux is nearly completely dependent on renal clearance; thus, it is contraindicated in patients with renal insufficiency $(\mathrm{CrCl}<30 \mathrm{~mL} / \mathrm{min})$.

1.3.3 Dosing and Monitoring: Fondaparinux is given at a fixed dose of $2.5 \mathrm{mg}$ daily for thromboprophylaxis and for the treatment of acute coronary syndromes. For treatment of DVT or pulmonary embolism, the drug is given at a dose of $7.5 \mathrm{mg}$ for patients with a body weight of 50 to $100 \mathrm{~kg}$; the dose is decreased to $5 \mathrm{mg}$ for patients weighing $<50 \mathrm{~kg}$ and increased to $10 \mathrm{mg}$ in those weighing $>100 \mathrm{~kg}$.

Fondaparinux has not been monitored in clinical studies. Therefore, routine coagulation monitoring is not recommended. In patients with moderate renal insufficiency (ie, $\mathrm{CrCl} 30-50 \mathrm{~mL} / \mathrm{min}$ ) who require thromboprophylaxis, the dose of fondaparinux should be reduced by $50 \%$ or low-dose heparin should be used in place of fondaparinux.

Although coagulation monitoring is not recommended on a routine basis, there may be circumstances in which it is useful to determine the anticoagulant activity of fondaparinux. This can be measured using fondaparinux-specific anti-Xa assays. The therapeutic anti-Xa range for fondaparinux has not been established. However, when given at the $2.5 \mathrm{mg}$ daily dose, the peak steady-state plasma concentration is, on average, 0.39 to $0.50 \mathrm{mg} / \mathrm{L}$ and is reached approximately $3 \mathrm{~h}$ post dose. For patients receiving therapeutic doses of fondaparinux (eg, $7.5 \mathrm{mg}$ daily for an individual of average body weight), the mean peak steady-state plasma concentration can be expected to be 1.20 to $1.26 \mathrm{mg} / \mathrm{L} 3 \mathrm{~h}$ post dose.

Fondaparinux does not bind to protamine sulfate, the antidote for heparin. If uncontrollable bleeding occurs with fondaparinux, recombinant factor VIIa may be effective. ${ }^{202}$

1.3.4 Nonhemorrhagic Side Effects: Fondaparinux has low affinity for PF4 and does not cross-react with HIT antibodies. ${ }^{203}$ Although there have been isolated case reports of HIT associated with the use of fondaparinux ${ }^{204,205}$ and reports of HIT antibodies without thrombocytopenia in patients given prophylaxis with fondaparinux, ${ }^{206}$ numerous case reports and case series suggest that this agent can be used to treat patients with HIT. ${ }^{207}$ This issue is further discussed in the article on HIT by Linkins et al ${ }^{32}$ in this supplement and has been summarized by Blackmer et al. ${ }^{205}$
Heparin and LMWH can cause urticarial skin reactions. Rarely, skin necrosis can occur at sites of injection. In these cases, HIT should be suspected. In a single case report, fondaparinux was used successfully in a patient who developed skin reactions to three different LMWH preparations. ${ }^{209}$

To date, studies on the effects of fondaparinux on bone metabolism have been limited to in vitro experiments using cultured osteoblasts. In one study, fondaparinux was compared with heparin, dalteparin, or enoxaparin. Osteoblasts exposed to fondaparinux showed significantly higher mitochondrial activity and protein synthesis than unexposed osteoblasts. In contrast, therapeutically relevant concentrations of heparin, dalteparin, or enoxaparin decreased matrix collagen type 2 content and calcification; fondaparinux had no effect on these measures of osteoblastic activity. ${ }^{210} \mathrm{~A}$ second study compared the effects of fondaparinux and dalteparin on human osteoblasts in culture. Dalteparin inhibited osteoblast proliferation, protein synthesis, and the decreased levels of osteocalcin and alkaline phosphatase. In contrast, fondaparinux had no effect. ${ }^{211}$

Because of insufficient safety data, fondaparinux is not widely used in pregnancy. Although one pharmacologic study showed that there was no placental transfer of the pentasacccharide, ${ }^{212}$ low levels of anti-Xa activity were detected in the umbilical cord blood in newborns of mothers treated with fondaparinux. ${ }^{213}$

\subsection{Danaparoid Sodium}

Although it is a mixture of glycosaminoglycans (heparan sulfate, dermatan sulfate, and chondroitin sulfate), danaparoid acts as an anticoagulant primarily by catalyzing the inhibition of factor $\mathrm{Xa}$ in an AT-dependent fashion. The drug has low specific anti-Xa activity. Based on anti-Xa levels, danaparoid has a half-life of approximately $25 \mathrm{~h}$.

Although danaparoid was shown to be effective for the prevention of venous thrombosis in high-risk patients, it is no longer marketed for this indication. Currently, its use is limited to the management of patients with HIT; it is discussed in greater detail in the article on HIT in this supplement. ${ }^{32}$ Danaparoid is the only agent that has been evaluated for HIT in a randomized clinical trial, wherein it was reported to be significantly better than dextran. High success rates in the treatment of HIT have also been observed in retrospective studies. Danaparoid is approved for the treatment of HIT in some countries (eg, The Netherlands, Belgium, New Zealand) but not in the United States.

Danaparoid does not prolong the INR. This facilitates monitoring when transitioning patients with 
HIT from danaparoid to vitamin $\mathrm{K}$ antagonists. The long half-life of danaparoid is a disadvantage if patients require urgent surgery or invasive procedures. It also is problematic if patients have serious bleeding because there is no antidote for danaparoid.

\subsection{Direct Thrombin InHibitors}

In contrast to indirect anticoagulants, which require a plasma cofactor to exert their activity, direct thrombin inhibitors have intrinsic activity because they bind to thrombin and block its enzymatic activity. The currently approved direct thrombin inhibitors are hirudin, bivalirudin, and argatroban.

\section{Hirudin}

A 65-amino acid polypeptide originally isolated from the salivary glands of the medicinal leech, Hirudo medicinalis, ${ }^{214,215}$ hirudin is now available in recombinant forms. Expressed in yeast, recombinant hirudins differ from native hirudin in that the Tyr residue at position 63 is not sulfated. Two recombinant forms of hirudin, known as lepirudin and desirudin, are currently approved for clinical use in North America and in Europe, respectively. Lepirudin is licensed for treatment of thrombosis complicating HIT, whereas desirudin is approved in Europe and the United States for postoperative thromboprophylaxis in patients undergoing elective hip arthroplasty.

Although there are minor differences in the aminoterminal composition of the two forms of recombinant hirudin, their mechanism of action and pharmacokinetic properties are identical. Both inhibit thrombin in a bivalent fashion. Thus, their globular aminoterminal domains interact with the active site of thrombin, whereas the anionic carboxy-terminal tails bind to exosite 1 on thrombin, the substrate-binding site. ${ }^{215}$ Both lepirudin and desirudin form high-affinity 1:1 stoichiometric complexes with thrombin that are essentially irreversible.

Dosing and Monitoring: The recommended dose of IV lepirudin for HIT is $0.15 \mathrm{mg} / \mathrm{kg} / \mathrm{h}$ with or without an initial bolus of $0.4 \mathrm{mg} / \mathrm{kg}$. The anticoagulant effect of lepirudin in this setting is monitored by using the aPTT, and the dose is adjusted to achieve a target aPTT ratio of 1.5 to 2.5 times control (Linkins et al). ${ }^{32}$ When given for thromboprophylaxis after elective hip replacement surgery, desirudin is given subcutaneously at a dose of $15 \mathrm{mg}$ twice daily without monitoring.

The plasma half-life of the hirudins is $60 \mathrm{~min}$ after IV injection and 120 min after subcutaneous injection. ${ }^{216}$ Hirudin is cleared via the kidneys, and the drug accumulates rapidly in patients with renal insufficiency. The dose of hirudin must be reduced when the CrCL is $<60 \mathrm{~mL} / \mathrm{min}$, and the drug is contraindicated in patients with renal failure. ${ }^{216}$ In a retrospective observational analysis of 181 patients with confirmed HIT who were treated with lepirudin at a mean dose of $0.06 \mathrm{mg} / \mathrm{kg} / \mathrm{h}$ for a median treatment duration of 7.7 days, $13.8 \%$ suffered a thrombotic event and $20.4 \%$ suffered major hemorrhage. The mean aPTT ratio was $>1.5$ in $>99 \%$ of patients. ${ }^{217}$

Antibodies against hirudin develop in up to $40 \%$ of patients treated with lepirudin. Although most of these antibodies have no clinical impact, some can prolong the plasma half-life of lepirudin, resulting in drug accumulation. In addition, anaphylaxis can occur if patients with antibodies are re-exposed to hirudin. Consequently, an alternative anticoagulant should be considered in patients with HIT who have previously been treated with hirudin.

\section{Bivalirudin}

A 20-amino acid synthetic polypeptide, bivalirudin is an analog of hirudin. ${ }^{218}$ The amino terminal D-PhePro-Arg-Pro sequence, which binds to the active site of thrombin, is connected via four Gly residues to a carboxy-terminal dodecapeptide that interacts with exosite 1 on thrombin. ${ }^{219}$ Like hirudin, bivalirudin forms a 1:1 stoichiometric complex with thrombin. However, once bound, thrombin cleaves the Pro-Arg bond within the amino terminal of bivalirudin, thereby allowing recovery of thrombin activity. ${ }^{220}$ Bivalirudin has a plasma half-life of 25 min after IV injection, ${ }^{221}$ and only $20 \%$ is excreted via the kidneys. ${ }^{222}$

Bivalirudin is licensed as an alternative to heparin in patients undergoing percutaneous interventions for unstable angina or non-ST-elevation or ST-elevation myocardial infarction and in patients with HIT (with or without thrombosis) who require percutaneous coronary interventions. ${ }^{223}$ The currently recommended dose is a bolus of $0.75 \mathrm{mg} / \mathrm{kg}$ followed by an infusion of $1.75 \mathrm{mg} / \mathrm{kg} / \mathrm{h}$ for the duration of the procedure. Dose reduction should be considered in patients with moderate to severe renal impairment. The drug has also been explored as an alternative to heparin in patients undergoing cardiopulmonary bypass surgery. In contrast to hirudin, bivalirudin is not immunogenic. However, antibodies against hirudin can cross-react with bivalirudin in vitro. The clinical consequences of this cross-reactivity are uncertain.

\section{Argatroban}

Argatroban is a small molecule competitive inhibitor of thrombin (molecular weight, $500 \mathrm{kDa}$ ). It 
binds noncovalently to the active site of thrombin to form a reversible complex. ${ }^{224-226}$ The plasma half-life of argatroban is $45 \mathrm{~min}$. It is metabolized in the liver ${ }^{226}$ via the cytochrome P450 3A4/5 enzyme system. Consequently, argatroban must be used with caution in patients with hepatic dysfunction. Because it is not renally excreted, however, argatroban is particularly useful in patients with HIT with severe renal impairment.

Argatroban is licensed for treatment and prevention of HIT-associated thrombosis and for anticoagulation during percutaneous coronary interventions when heparin is contraindicated because of a recent history of HIT. Argatroban is given as a continuous IV infusion with an initial dose of 1 to $2 \mu \mathrm{g} / \mathrm{kg} / \mathrm{min}$ and the dose is adjusted to maintain the aPTT ratio in the 1.5 to 2.5 range (Linkins et al). ${ }^{32}$

\subsection{Monitoring of Direct Thrombin Inhibitors}

Although the aPTT is used to monitor therapy with direct thrombin inhibitors, this test is not ideal. The dose-response is not linear and the aPTT reaches a plateau with higher doses of the various drugs. In addition, aPTT reagents vary in their sensitivities to direct thrombin inhibitors. The ecarin clotting time yields a more linear dose-response, but this test is not widely available and has not been standardized.

All of the direct thrombin inhibitors increase the INR, albeit to a variable extent. When given in therapeutic doses, argatroban has the greatest effect on the INR. ${ }^{227}$ This phenomenon complicates transitioning from argatroban to vitamin $\mathrm{K}$ antagonists. To overcome this problem, the INR can be measured after stopping the argatroban infusion for several hours. Because holding argatroban may expose patients to a risk of thrombosis, another option is to monitor the vitamin $\mathrm{K}$ antagonist with a chromogenic factor X assay. In this setting, factor X levels $<45 \%$ have been associated with INR values $>2$ when the effect of argatroban has been eliminated. ${ }^{228}$ Monitoring factor $\mathrm{X}$ levels may be safer than aiming for an INR $\geq 4$ when vitamin $K$ antagonists are given in conjunction with argatroban. ${ }^{229,230}$

\subsection{Reversal of Anticoagulant Effects}

There are no specific antidotes for direct thrombin inhibitors. Using inhibition of thrombin generation in whole blood recovered from a bleeding time incision as an index of activity, recombinant factor VIIa can reverse the anticoagulant effect of direct thrombin inhibitors in healthy volunteers. ${ }^{231}$ Although recombinant factor VIIa reduces bleeding induced by direct thrombin inhibitors in animals, the usefulness of this agent in patients who are bleeding has not been established.
Hemodialysis or hemoperfusion can remove bivalirudin or argatroban. Dialysis using "high-flux" dialysis membranes can clear hirudin.

\section{ACKNOWLEDGMENTS}

Author Contributions: As Topic Editor, Dr Garcia oversaw the development of this article, including any analysis and subsequent development of the information contained herein.

Dr Garcia: contributed as a Topic Editor.

Dr Baglin: contributed as a panelist.

Dr Weitz: contributed as a panelist.

Dr Samama: contributed as a panelist.

Financial/nonfinancial disclosures: In summary, the authors have reported to CHEST the following conflicts of interest: Drs Weitz and Garcia have served as consultants for Boehringer Ingelheim, Bristol-Myers Squibb, Pfizer, Daiichi-Sankyo, Bayer, and Johnson \& Johnson. Dr Samama has received honoraria for lectures or consulting from Bayer Healthcare, Johnson \& Johnson, BristolMyers Squibb, Boehringer Ingelheim, sanofi-aventis, and Rovi, and has served on a steering committee for Daiichi-Sankyo. Dr Baglin has reported that no potential conflicts of interest exist with any companies/organizations whose products or services may be discussed in this article.

Role of sponsors: The sponsors played no role in the development of these guidelines. Sponsoring organizations cannot recommend panelists or topics, nor are they allowed prepublication access to the manuscripts and recommendations. Guideline panel members, including the chair, and members of the Health \& Science Policy Committee are blinded to the funding sources. Further details on the Conflict of Interest Policy are available online at http://chestnet.org. Endorsements: This guideline is endorsed by the American Association for Clinical Chemistry, the American College of Clinical Pharmacy, the American Society of Health-System Pharmacists, the American Society of Hematology, and the International Society of Thrombosis and Hematosis.

\section{REFERENCES}

1. McLean J. The thromboplastic action of cephalin. Am J Physiol. 1916;41:250-257.

2. Brinkhous K, Smith H, Warner E, et al. The inhibition of blood clotting: an unidentified substance which acts in conjunction with heparin to prevent the conversion of prothrombin into thrombin. Am J Physiol. 1939;125:683-687.

3. Abildgaard U. Highly purified antithrombin 3 with heparin cofactor activity prepared by disc electrophoresis. Scand J Clin Lab Invest. 1968;21(1):89-91.

4. Lindahl U, Bäckström G, Höök M, Thunberg L, Fransson LA, Linker A. Structure of the antithrombin-binding site in heparin. Proc Natl Acad Sci U S A. 1979;76(7):3198-3202.

5. Merlini PA, Bauer KA, Oltrona L, et al. Persistent activation of coagulation mechanism in unstable angina and myocardial infarction. Circulation. 1994;90(1):61-68.

6. Rosenberg RD, Lam L. Correlation between structure and function of heparin. Proc Natl Acad Sci U S A. 1979;76(3): 1218-1222.

7. Hirsh J, Bauer KA, Donati MB, et al. Parenteral anticoagulants: American College of Chest Physicians evidence-based clinical practice guidelines (8th edition). Chest. 2008;133(6 suppl):141S-159S.

8. Andersson LO, Barrowcliffe TW, Holmer E, Johnson EA, Sims GE. Anticoagulant properties of heparin fractionated by affinity chromatography on matrix-bound antithrombin iii and by gel filtration. Thromb Res. 1976;9(6):575-583.

9. Harenberg J. Pharmacology of low molecular weight heparins. Semin Thromb Hemost. 1990;16(suppl):12-18.

10. Johnson EA, Kirkwood TB, Stirling Y, et al. Four heparin preparations: anti-Xa potentiating effect of heparin after subcutaneous injection. Thromb Haemost. 1976;35(3):586-591. 
11. Lam LH, Silbert JE, Rosenberg RD. The separation of active and inactive forms of heparin. Biochem Biophys Res Commun. 1976;69(2):570-577.

12. Tollefsen DM, Majerus DW, Blank MK. Heparin cofactor II. Purification and properties of a heparin-dependent inhibitor of thrombin in human plasma. J Biol Chem. 1982; 257(5):2162-2169.

13. Hirsh J, Weitz JI. New antithrombotic agents. Lancet. 1999;353(9162):1431-1436.

14. Casu B, Oreste P, Torri G, et al. The structure of heparin oligosaccharide fragments with high anti-(factor $\mathrm{Xa}$ ) activity containing the minimal antithrombin III-binding sequence. Chemical and 13C nuclear-magnetic-resonance studies. Biochem J. 1981;197(3):599-609.

15. Lane DA, Denton J, Flynn AM, Thunberg L, Lindahl U. Anticoagulant activities of heparin oligosaccharides and their neutralization by platelet factor 4. Biochem J. 1984; 218(3):725-732.

16. Lindahl U, Thunberg L, Bäckström G, Riesenfeld J, Nordling K, Björk I. Extension and structural variability of the antithrombin-binding sequence in heparin. J Biol Chem. 1984;259(20):12368-12376.

17. Nesheim ME. A simple rate law that describes the kinetics of the heparin-catalyzed reaction between antithrombin III and thrombin. J Biol Chem. 1983;258(23):14708-14717.

18. Oosta GM, Gardner WT, Beeler DL, Rosenberg RD. Multiple functional domains of the heparin molecule. Proc Natl Acad Sci U S A. 1981;78(2):829-833.

19. Béguin S, Lindhout T, Hemker HC. The mode of action of heparin in plasma. Thromb Haemost. 1988;60(3):457-462.

20. Blajchman MA, Young E, Ofosu FA. Effects of unfractionated heparin, dermatan sulfate and low molecular weight heparin on vessel wall permeability in rabbits. Ann $N$ Y Acad Sci. 1989;556:245-254.

21. Ofosu FA, Sie P, Modi GJ, et al. The inhibition of thrombin-dependent positive-feedback reactions is critical to the expression of the anticoagulant effect of heparin. Biochem J. 1987;243(2):579-588.

22. Eika C. Inhibition of thrombin induced aggregation of human platelets by heparin. Scand J Haematol. 1971;8(3): 216-222.

23. Kelton JG, Hirsh J. Bleeding associated with antithrombotic therapy. Semin Hematol. 1980;17(4):259-291.

24. Salzman EW, Rosenberg RD, Smith MH, Lindon JN, Favreau L. Effect of heparin and heparin fractions on platelet aggregation. J Clin Invest. 1980;65(1):64-73.

25. Heiden D, Mielke CH Jr, Rodvien R. Impairment by heparin of primary haemostasis and platelet [14C]5-hydroxytryptamine release. Br J Haematol. 1977;36(3):427-436.

26. Fernandez F, N'guyen P, Van Ryn J, Ofosu FA, Hirsh J, Buchanan MR. Hemorrhagic doses of heparin and other glycosaminoglycans induce a platelet defect. Thromb Res. 1986;43(4):491-495.

27. Hull R, Hirsh J, Jay R, et al. Different intensities of oral anticoagulant therapy in the treatment of proximal-vein thrombosis. N Engl J Med. 1982;307(27):1676-1681.

28. Castellot JJ Jr, Favreau LV, Karnovsky MJ, Rosenberg RD. Inhibition of vascular smooth muscle cell growth by endothelial cell-derived heparin. Possible role of a platelet endoglycosidase. J Biol Chem. 1982;257(19):11256-11260.

29. Clowes AW, Karnowsky MJ. Suppression by heparin of smooth muscle cell proliferation in injured arteries. Nature. 1977;265(5595):625-626.

30. Bhandari M, Hirsh J, Weitz JI, Young E, Venner TJ, Shaughnessy SG. The effects of standard and low molecular weight heparin on bone nodule formation in vitro. Thromb Haemost. 1998;80(3):413-417.
31. Shaughnessy SG, Young E, Deschamps P, Hirsh J. The effects of low molecular weight and standard heparin on calcium loss from fetal rat calvaria. Blood. 1995;86(4):1368-1373.

32. Linkins L-A, Dans AL, Moores LK, et al. Treatment and prevention of heparin-induced thrombocytopenia: antithrombotic therapy and prevention of thrombosis, 9th ed: American College of Chest Physicians evidence-based clinical practice guidelines. Chest. 2012;141(2)(suppl):e495S-e530S.

33. Berkowitz SD. Treatment of established deep vein thrombosis: a review of the therapeutic armamentarium. Orthopedics. 1995;18(suppl):18-20.

34. Pini M, Pattachini C, Quintavalla R, et al. Subcutaneous vs intravenous heparin in the treatment of deep venous thrombosis-a randomized clinical trial. Thromb Haemost. 1990;64(2):222-226.

35. Kearon C, Ginsberg JS, Julian JA, et al; Fixed-Dose Heparin (FIDO) Investigators. Comparison of fixed-dose weightadjusted unfractionated heparin and low-molecular-weight heparin for acute treatment of venous thromboembolism. JAMA. 2006;296(8):935-942.

36. Bara L, Billaud E, Gramond G, Kher A, Samama M. Comparative pharmacokinetics of a low molecular weight heparin (PK 10 169) and unfractionated heparin after intravenous and subcutaneous administration. Thromb Res. 1985;39(5):631-636.

37. Powers PJ, Gent M, Jay RM, et al. A randomized trial of less intense postoperative warfarin or aspirin therapy in the prevention of venous thromboembolism after surgery for fractured hip. Arch Intern Med. 1989;149(4):771-774.

38. Hirsh J, van Aken WG, Gallus AS, Dollery CT, Cade JF, Yung WL. Heparin kinetics in venous thrombosis and pulmonary embolism. Circulation. 1976;53(4):691-695.

39. Brey RL. Antiphospholipid antibodies and ischemic stroke. Heart Dis Stroke. 1992;1(6):379-382.

40. Bârzu T, Molho P, Tobelem G, Petitou M, Caen J. Binding and endocytosis of heparin by human endothelial cells in culture. Biochim Biophys Acta. 1985;845(2):196-203.

41. Sobel M, McNeill PM, Carlson PL, et al. Heparin inhibition of von Willebrand factor-dependent platelet function in vitro and in vivo. J Clin Invest. 1991;87(5):1787-1793.

42. Bjornsson TD, Wolfram KM, Kitchell BB. Heparin kinetics determined by three assay methods. Clin Pharmacol Ther. 1982;31(1):104-113.

43. de Swart CA, Nijmeyer B, Roelofs JM, Sixma JJ. Kinetics of intravenously administered heparin in normal humans. Blood. 1982;60(6):1251-1258.

44. Olsson P, Lagergren H, Ek S. The elimination from plasma of intravenous heparin. An experimental study on dogs and humans. Acta Med Scand. 1963;173:619-630.

45. Mahadoo J, Heibert L, Jaques LB. Vascular sequestration of heparin. Thromb Res. 1978;12(1):79-90.

46. Friedman Y, Arsenis C. Studies on the heparin sulphamidase activity from rat spleen. Intracellular distribution and characterization of the enzyme. Biochem J. 1974;139(3):699-708.

47. Dawes J, Papper DS. Catabolism of low-dose heparin in man. Thromb Res. 1979;14(6):845-860.

48. McAllister BM, Demis DJ. Heparin metabolism: isolation and characterization of uroheparin. Nature. 1966;212(5059): 293-294.

49. Raschke RA, Reilly BM, Guidry JR, Fontana JR, Srinivas S. The weight-based heparin dosing nomogram compared with a "standard care" nomogram. A randomized controlled trial. Ann Intern Med. 1993;119(9):874-881.

50. Smith SB, Geske JB, Maguire JM, Zane NA, Carter RE, Morgenthaler TI. Early anticoagulation is associated with reduced mortality for acute pulmonary embolism. Chest. 2010;137(6):1382-1390. 
51. Cruickshank MK, Levine MN, Hirsh J, Roberts R, Siguenza M. A standard heparin nomogram for the management of heparin therapy. Arch Intern Med. 1991;151(2):333-337.

52. Prandoni P, Carnovali M, Marchiori A; Galilei Investigators. Subcutaneous adjusted-dose unfractionated heparin vs fixeddose low-molecular-weight heparin in the initial treatment of venous thromboembolism. Arch Intern Med. 2004;164(10): 1077-1083.

53. Braunwald E, Antman E, Beasley J, et al. ACC/AHA Guidelines for the management of patients with unstable angina and non-ST-segment elevation myocardial infarction. A report of the American College of Cardiology/American Heart Association Task Force on Practice Guidelines. J Am Coll Cardiol. 2000;36(3):970-1062.

54. Ryan T, Antman E, Brooks N, et al. 1999 update: ACC/ AHA guidelines for the management of patients with acute myocardial infarction. A report of the American College of Cardiology/American Heart Association Task Force on Practice Guidelines. J Am Coll Cardiol. 1999;34(3): 890-911.

55. Levine M, Hirsh J, Kelton J. Heparin-induced bleeding. In: Land DA, Lindahl U, eds. Heparin: Chemical and Biological Properties, Clinical Applications. London, England: Edward Arnold; 1989:517-532.

56. Morabia A. Heparin doses and major bleedings. Lancet. 1986;1(8492):1278-1279.

57. Antman EM. the TIMI 9A Investigators. Hirudin in acute myocardial infarction. Safety report from the Thrombolysis and Thrombin Inhibition in Myocardial Infarction (TIMI) 9A trial. Circulation. 1994;90(4):1624-1630.

58. Antman EM. Hirudin in acute myocardial infarction. Thrombolysis and Thrombin Inhibition in Myocardial Infarction (TIMI) 9B trial. Circulation. 1996;94(5):911-921.

59. GUSTO IIA Investigators. Randomized trial of intravenous heparin versus recombinant hirudin for acute coronary syndromes. The Global Use of Strategies to Open Occluded Coronary Arteries (GUSTO) IIa Investigators. Circulation. 1994;90(4):1631-1637.

60. GUSTO IIB Investigators. A comparison of recombinant hirudin with heparin for the treatment of acute coronary syndromes. The Global Use of Strategies to Open Occluded Coronary Arteries (GUSTO) IIb investigators. N Engl J Med. 1996;335(11):775-782.

61. EPIC Investigators. Use of a monoclonal antibody directed against the platelet glycoprotein IIb/IIIa receptor in highrisk coronary angioplasty. The EPIC Investigation. $N$ Engl J Med. 1994;330(14):956-961.

62. EPILOG Investigators. Platelet glycoprotein IIb/IIIa receptor blockade and low-dose heparin during percutaneous coronary revascularization. N Engl J Med. 1997;336(24): 1689-1696.

63. Landefeld CS, Cook EF, Flatley M, Weisberg M, Goldman L. Identification and preliminary validation of predictors of major bleeding in hospitalized patients starting anticoagulant therapy. Am J Med. 1987;82(4):703-713.

64. Landefeld CS, McGuire E III, Rosenblatt MW. A bleeding risk index for estimating the probability of major bleeding in hospitalized patients starting anticoagulant therapy. Am J Med. 1990;89(5):569-578.

65. Raschke RA, Gollihare B, Peirce JC. The effectiveness of implementing the weight-based heparin nomogram as a practice guideline. Arch Intern Med. 1996;156(15):1645-1649.

66. Basu D, Gallus A, Hirsh J, Cade J. A prospective study of the value of monitoring heparin treatment with the activated partial thromboplastin time. N Engl J Med. 1972;287(7):324-327.

67. Bain B, Forster T, Sleigh B. Heparin and the activated partial thromboplastin time-a difference between the in-vitro and in-vivo effects and implications for the therapeutic range. Am J Clin Pathol. 1980;74(5):668-673.

68. Baker BA, Adelman MD, Smith PA, Osborn JC. Inability of the activated partial thromboplastin time to predict heparin levels. Time to reassess guidelines for heparin assays. Arch Intern Med. 1997;157(21):2475-2479.

69. Bates SM, Weitz JI, Johnston M, Hirsh J, Ginsberg JS. Use of a fixed activated partial thromboplastin time ratio to establish a therapeutic range for unfractionated heparin. Arch Intern Med. 2001;161(3):385-391.

70. Brandt JT, Triplett DA. Laboratory monitoring of heparin. Effect of reagents and instruments on the activated partial thromboplastin time. Am J Clin Pathol. 1981;76(4 suppl):530-537.

71. Brill-Edwards P, Ginsberg JS, Johnston M, Hirsh J. Establishing a therapeutic range for heparin therapy. Ann Intern Med. 1993;119(2):104-109.

72. Kitchen S, Jennings I, Woods TA, Preston FE. Wide variability in the sensitivity of aPTT reagents for monitoring of heparin dosage. J Clin Pathol. 1996;49(1):10-14.

73. Olson JD, Arkin CF, Brandt JT, et al. College of American Pathologists Conference XXXI on laboratory monitoring of anticoagulant therapy: laboratory monitoring of unfractionated heparin therapy. Arch Pathol Lab Med. 1998;122(9):782-798.

74. Rosborough TK. Comparing different lots of activated partial thromboplastin time reagent: analysis of two methods. Am J Clin Pathol. 1998;110(2):173-177.

75. Shojania AM, Tetreault J, Turnbull G. The variations between heparin sensitivity of different lots of activated partial thromboplastin time reagent produced by the same manufacturer. Am J Clin Pathol. 1988;89(1):19-23.

76. Zanke B, Shojania AM. Comparison of two aPTT methods of monitoring heparin therapy. aPTT ratio and heparin response of pooled normal plasma. Am J Clin Pathol. 1990;93(5):684-689.

77. Koerber JM, Smythe MA, Begle RL, Mattson JC, Kershaw BP, Westley SJ. Correlation of activated clotting time and activated partial thromboplastin time to plasma heparin concentration. Pharmacotherapy. 1999;19(8):922-931.

78. Manzato F, Mengoni A, Grilenzoni A, Lippi G. Evaluation of the activated partial thromboplastin time (aPTT) sensitivity to heparin using five commercial reagents: implications for therapeutic monitoring. Clin Chem Lab Med. 1998;36(12):975-980.

79. Raschke RA, Guidry JR, Foley MR. Apparent heparin resistance from elevated factor VIII during pregnancy. Obstet Gynecol. 2000;96(5 pt 2):804-806.

80. Rosborough TK. Comparison of anti-factor Xa heparin activity and activated partial thromboplastin time in 2,773 plasma samples from unfractionated heparin-treated patients. Am J Clin Pathol. 1997;108(6):662-668.

81. Volles DF, Ancell CJ, Michael KA, Mullins DM, Humphries JE. Establishing an institution-specific therapeutic range for heparin. Am J Health Syst Pharm. 1998;55(19):2002-2006.

82. Guidry JR, Raschke RA, Morkunas AR. Toxic effects of drugs used in the ICU. Anticoagulants and thrombolytics. Risks and benefits [review]. Crit Care Clin. 1991;7(3): 533-554.

83. van den Besselaar AM, Meeuwisse-Braun J, Bertina RM. Monitoring heparin therapy: relationships between the activated partial thromboplastin time and heparin assays based on ex-vivo heparin samples. Thromb Haemost. 1990; 63(1):16-23.

84. Cuker A, Raby A, Moffat KA, Flynn G, Crowther MA. Interlaboratory variation in heparin monitoring: Lessons from the Quality Management Program of Ontario coagulation surveys. Thromb Haemost. 2010;104(4):837-844. 
85. Cuker A, Ptashkin B, Konkle BA, et al. Interlaboratory agreement in the monitoring of unfractionated heparin using the anti-factor Xa-correlated activated partial thromboplastin time. J Thromb Haemost. 2009;7(1):80-86.

86. Anand SS, Brimble S, Ginsberg JS. Management of iliofemoral thrombosis in a pregnant patient with heparin resistance. Arch Intern Med. 1997;157(7):815-816.

87. Green D, Hirsh J, Heit J, Prins M, Davidson B, Lensing AW. Low molecular weight heparin: a critical analysis of clinical trials. Pharmacol Rev. 1994;46(1):89-109.

88. Levine MN, Hirsh J, Gent M, et al. A randomized trial comparing activated thromboplastin time with heparin assay in patients with acute venous thromboembolism requiring large daily doses of heparin. Arch Intern Med. 1994;154(1):49-56.

89. Whitfield LR, Lele AS, Levy G. Effect of pregnancy on the relationship between concentration and anticoagulant action of heparin. Clin Pharmacol Ther. 1983;34(1):23-28.

90. Edson JR, Krivit W, White JG. Kaolin partial thromboplastin time: high levels of procoagulants producing short clotting times or masking deficiencies of other procoagulants or low concentrations of anticoagulants. J Lab Clin Med. 1967;70(3):463-470.

91. Becker RC, Corrao JM, Bovill EG, et al. Intravenous nitroglycerin-induced heparin resistance: a qualitative antithrombin III abnormality. Am Heart J. 1990;119(6): 1254-1261.

92. Fisher AR, Bailey CR, Shannon CN, Wielogorski AK. Heparin resistance after aprotinin. Lancet. 1992;340(8829):1230-1231.

93. Albers GW, Atwood JE, Hirsh J, Sherman DG, Hughes RA, Connolly SJ. Stroke prevention in nonvalvular atrial fibrillation. Ann Intern Med. 1991;115(9):727-736.

94. Blossom DB, Kallen AJ, Patel PR, et al. Outbreak of adverse reactions associated with contaminated heparin. $N$ Engl J Med. 2008;359(25):2674-2684.

95. Li B, Suwan J, Martin JG, et al. Oversulfated chondroitin sulfate interaction with heparin-binding proteins: new insights into adverse reactions from contaminated heparins. Biochem Pharmacol. 2009;78(3):292-300.

96. Carlson MK, Gleason PP, Sen S. Elevation of hepatic transaminases after enoxaparin use: case report and review of unfractionated and low-molecular-weight heparin-induced hepatotoxicity. Pharmacotherapy. 2001;21(1):108-113.

97. Warkentin TE, Kelton JG. A 14-year study of heparininduced thrombocytopenia. Am J Med. 1996;101(5): 502-507.

98. Rajgopal R, Butcher M, Weitz JI, Shaughnessy SG. Heparin synergistically enhances interleukin-11 signaling through up-regulation of the MAPK pathway. J Biol Chem. 2006;281(30):20780-20787.

99. American Society of Heath-system Pharmacists. Protamine Sulfate: Antiheparin Agents. Bethesda, MD: American Society of Health-system Pharmacists; 1999.

100. Caplan SN, Berkman EM. Letter: Protamine sulfate and fish allergy. N Engl J Med. 1976;295(3):172.

101. Lytle BW, Cosgrove DM, Taylor PC, et al. Reoperations for valve surgery: perioperative mortality and determinants of risk for 1,000 patients, 1958-1984. Ann Thorac Surg. 1986;42(6):632-643.

102. Cooney A, Mann TJ. Recent experiences with hexadimethrine for neutralizing heparin after cardiopulmonary bypass. Anaesth Intensive Care. 1999;27(3):298-300.

103. Kikura M, Lee MK, Levy JH. Heparin neutralization with methylene blue, hexadimethrine, or vancomycin after cardiopulmonary bypass. Anesth Analg. 1996;83(2):223-227.

104. Despotis GJ, Summerfield AL, Joist JH, et al. In vitro reversal of heparin effect with heparinase: evaluation with whole blood prothrombin time and activated partial thromboplastin time in cardiac surgical patients. Anesth Analg. 1994;79(4):670-674.

105. D'Ambra M. Restoration of the normal coagulation process: advances in therapies to antagonize heparin. J Cardiovasc Pharmacol. 1996;27(suppl 1):S58-S62.

106. Dehmer GJ, Fisher M, Tate DA, Teo S, Bonnem EM. Reversal of heparin anticoagulation by recombinant platelet factor 4 in humans. Circulation. 1995;91(8):2188-2194.

107. Tao W, Deyo DJ, Brunston RL Jr, Vertrees RA, Zwischenberger JB. Extracorporeal heparin adsorption following cardiopulmonary bypass with a heparin removal device-an alternative to protamine. Crit Care Med. 1998;26(6):1096-1102.

108. Hulin MS, Wakefield TW, Andrews PC, et al. A novel protamine variant reversal of heparin anticoagulation in human blood in vitro. J Vasc Surg. 1997;26(6):1043-1048.

109. Holmer E, Kurachi K, Söderström G. The molecularweight dependence of the rate-enhancing effect of heparin on the inhibition of thrombin, factor Xa, factor IXa, factor XIa, factor XIIa and kallikrein by antithrombin. Biochem J. 1981;193(2):395-400.

110. Holmer E, Söderberg K, Bergqvist D, Lindahl U. Heparin and its low molecular weight derivatives: anticoagulant and antithrombotic properties. Haemostasis. 1986;16(suppl 2):1-7.

111. Jordan RE, Oosta GM, Gardner WT, Rosenberg RD. The kinetics of hemostatic enzyme-antithrombin interactions in the presence of low molecular weight heparin. J Biol Chem. 1980;255(21):10081-10090.

112. Bergqvist D, Nilsson B, Hedner U, Pedersen PC, Ostergaard $\mathrm{PB}$. The effect of heparin fragments of different molecular weights on experimental thrombosis and haemostasis. Thromb Res. 1985;38(6):589-601.

113. Carter CJ, Kelton JG, Hirsh J, Cerskus A, Santos AV, Gent M. The relationship between the hemorrhagic and antithrombotic properties of low molecular weight heparin in rabbits. Blood. 1982;59(6):1239-1245.

114. van Dongen CJ, van den Belt AG, Prins MH, Lensing AW. Fixed dose subcutaneous low molecular weight heparins versus adjusted dose unfractionated heparin for venous thromboembolism. Cochrane Database Syst Rev. 2004;18(4):CD001100.

115. Bara L, Samama M. Pharmacokinetics of low molecular weight heparins. Acta Chir Scand Suppl. 1988;543:65-72.

116. Bradbrook ID, Magnani HN, Moelker HC, et al. ORG 10172: a low molecular weight heparinoid anticoagulant with a long half-life in man. Br J Clin Pharmacol. 1987;23(6): 667-675.

117. Bratt G, Törnebohm E, Widlund L, Lockner D. Low molecular weight heparin (KABI 2165, Fragmin): pharmacokinetics after intravenous and subcutaneous administration in human volunteers. Thromb Res. 1986;42(5):613-620.

118. Briant L, Caranobe C, Saivin S, et al. Unfractionated heparin and CY 216: pharmacokinetics and bioavailabilities of the antifactor Xa and IIa effects after intravenous and subcutaneous injection in the rabbit. Thromb Haemost. 1989;61(3):348-353.

119. Frydman AM, Bara L, Le Roux Y, Woler M, Chauliac F, Samama MM. The antithrombotic activity and pharmacokinetics of enoxaparine, a low molecular weight heparin, in humans given single subcutaneous doses of 20 to $80 \mathrm{mg}$. J Clin Pharmacol. 1988;28(7):609-618.

120. Mätzsch T, Bergqvist D, Hedner U, Ostergaard P. Effects of an enzymatically depolymerized heparin as compared with conventional heparin in healthy volunteers. Thromb Haemost. 1987;57(1):97-101.

121. Weitz JI. Low-molecular-weight heparins. N Engl J Med. 1997;337(10):688-698. 
122. Anderson DR, O’Brien BJ, Levine MN, Roberts R, Wells PS, Hirsh J. Efficacy and cost of low-molecular-weight heparin compared with standard heparin for the prevention of deep vein thrombosis after total hip arthroplasty. Ann Intern Med. 1993;119(11):1105-1112.

123. Crowther MA, Ginsberg JB, Kearon C, et al. A randomized trial comparing 5-mg and 10-mg warfarin loading doses. Arch Intern Med. 1999;159(1):46-48.

124. Warkentin TE, Levine MN, Hirsh J, et al. Heparin-induced thrombocytopenia in patients treated with low-molecularweight heparin or unfractionated heparin. $N$ Engl J Med. 1995;332(20):1330-1335.

125. Choay J, Petitou M, Lormeau JC, Sinaÿ P, Casu B, Gatti G. Structure-activity relationship in heparin: a synthetic pentasaccharide with high affinity for antithrombin III and eliciting high anti-factor Xa activity. Biochem Biophys Res Commun. 1983;116(2):492-499.

126. Handeland GF, Abildgaard U, Holm HA, Arnesen KE. Dose adjusted heparin treatment of deep venous thrombosis: a comparison of unfractionated and low molecular weight heparin. Eur J Clin Pharmacol. 1990;39(2):107-112.

127. Boneu B, Caranobe C, Cadroy Y, et al. Pharmacokinetic studies of standard unfractionated heparin, and low molecular weight heparins in the rabbit. Semin Thromb Hemost. 1988; 14(1):18-27.

128. Palm M, Mattsson C. Pharmacokinetics of heparin and low molecular weight heparin fragment (Fragmin) in rabbits with impaired renal or metabolic clearance. Thromb Res. 1985;40:129-133.

129. Abbate R, Gori AM, Farsi A, Attanasio M, Pepe G. Monitoring of low-molecular-weight heparins in cardiovascular disease. Am J Cardiol. 1998;82(5B):33L-36L.

130. Francis CW, Pellegrini VD Jr, Totterman S, et al. Prevention of deep-vein thrombosis after total hip arthroplasty. Comparison of warfarin and dalteparin. J Bone Joint Surg Am. 1997;79(9):1365-1372.

131. Samama MM, Poller L. Contemporary laboratory monitoring of low molecular weight heparins. Clin Lab Med. 1995; 15(1):119-123.

132. Nieuwenhuis HK, Albada J, Banga JD, Sixma JJ. Identification of risk factors for bleeding during treatment of acute venous thromboembolism with heparin or low molecular weight heparin. Blood. 1991;78(9):2337-2343.

133. Bates SM, Greer IA, Middeldorp S, Veenstra D, Prabulos A-M, Vandvik PO. VTE, thrombophilia, antithrombotic therapy, and pregnancy: antithrombotic therapy and prevention of thrombosis, 9th ed: American College of Chest Physicians evidence-based clinical practice guidelines. Chest. 2012; 141(2)(suppl):e691S-e736S.

134. Bara L, Leizorovicz A, Picolet H, et al. Correlation between anti-Xa and occurrence of thrombosis and haemorrhage in postsurgical patients treated with either Logiparin or unfractionated heparin. Thromb Res. 1992;65(4-5):641-650.

135. Prandoni P, Lensing AW, Büller HR, et al. Comparison of subcutaneous low-molecular-weight heparin with intravenous standard heparin in proximal deep-vein thrombosis. Lancet. 1992;339(8791):441-445.

136. Walenga JM, Hoppensteadt D, Fareed J. Laboratory monitoring of the clinical effects of low molecular weight heparins. Thromb Res. 1991;14:49-62.

137. Alhenc-Gelas M, Jestin-Le Guernic C, Vitoux JF, Kher A, Aiach M, Fiessinger JN; Fragmin-Study Group. Adjusted versus fixed doses of the low-molecular-weight heparin fragmin in the treatment of deep vein thrombosis. Thromb Haemost. 1994;71(6):698-702.

138. Laposata M, Green D, Van Cott EM, Barrowcliffe TW, Goodnight SH, Sosolik RC. College of American Pathologists
Conference XXXI on laboratory monitoring of anticoagulant therapy: the clinical use and laboratory monitoring of low-molecular-weight heparin, danaparoid, hirudin and related compounds, and argatroban. Arch Pathol Lab Med. 1998;122(9):799-807.

139. Boneu B. Low molecular weight heparin therapy: is monitoring needed? Thromb Haemost. 1994;72(3):330-334.

140. Boneu B, de Moerloose P. How and when to monitor a patient treated with low molecular weight heparin. Semin Thromb Hemost. 2001;27(5):519-522.

141. Becker RC, Spencer FA, Gibson M, et al; TIMI 11A Investigators. Influence of patient characteristics and renal function on factor $\mathrm{Xa}$ inhibition pharmacokinetics and pharmacodynamics after enoxaparin administration in nonST-segment elevation acute coronary syndromes. Am Heart J. 2002;143(5):753-759.

142. Roman MJ, Shanker BA, Davis A, et al. Prevalence and correlates of accelerated atherosclerosis in systemic lupus erythematosus. N Engl J Med. 2003;349(25):2399-2406.

143. Wilson SJ, Wilbur K, Burton E, Anderson DR. Effect of patient weight on the anticoagulant response to adjusted therapeutic dosage of low-molecular-weight heparin for the treatment of venous thromboembolism. Haemostasis. 2001;31(1):42-48.

144. Hainer JW, Barrett JS, Assaid CA, et al. Dosing in heavyweight/obese patients with the LMWH, tinzaparin: a pharmacodynamic study. Thromb Haemost. 2002;87(5): 817-823.

145. de Denus S, Sanoski CA, Carlsson J, Opolski G, Spinler SA. Rate vs rhythm control in patients with atrial fibrillation: a meta-analysis. Arch Intern Med. 2005;165(3):258-262.

146. Frederiksen SG, Hedenbro JL, Norgren L. Enoxaparin effect depends on body-weight and current doses may be inadequate in obese patients. Br J Surg. 2003;90(5):547-548.

147. Heizmann M, Baerlocher GM, Steinmann F, Horber FF, Wuillemin W. Anti-Xa activity in obese patients after double standard dose of nadroparin for prophylaxis. Thromb Res. 2002;106(4-5):179-181.

148. Eichinger S, Hron G, Bialonczyk C, et al. Overweight, obesity, and the risk of recurrent venous thromboembolism. Arch Intern Med. 2008;168(15):1678-1683.

149. Kalfarentzos F, Stavropoulou F, Yarmenitis S, et al. Prophylaxis of venous thromboembolism using two different doses of low-molecular-weight heparin (nadroparin) in bariatric surgery: a prospective randomized trial. Obes Surg. 2001;11(6):670-676.

150. Scholten DJ, Hoedema RM, Scholten SE. A comparison of two different prophylactic dose regimens of low molecular weight heparin in bariatric surgery. Obes Surg. 2002;12(1):19-24.

151. Imberti D, Legnani C, Baldini E, et al. Pharmacodynamics of low molecular weight heparin in patients undergoing bariatric surgery: a prospective, randomised study comparing two doses of parnaparin (BAFLUX study). Thromb Res. 2009;124(6):667-671.

152. Simone EP, Madan AK, Tichansky DS, Kuhl DA, Lee MD. Comparison of two low-molecular-weight heparin dosing regimens for patients undergoing laparoscopic bariatric surgery. Surg Endosc. 2008;22(11):2392-2395.

153. Brophy DF, Wazny LD, Gehr TW, Comstock TJ, Venitz J. The pharmacokinetics of subcutaneous enoxaparin in endstage renal disease. Pharmacotherapy. 2001;21(2):169-174.

154. Goudable C, Saivin S, Houin G, et al. Pharmacokinetics of a low molecular weight heparin (Fraxiparine) in various stages of chronic renal failure. Nephron. 1991;59(4):543-545.

155. Chow SL, Zammit K, West K, Dannenhoffer M, LopezCandales A. Correlation of antifactor Xa concentrations with 
renal function in patients on enoxaparin. J Clin Pharmacol. 2003;43(6):586-590.

156. Sanderink GJ, Guimart CG, Ozoux M-L, Jariwala NU, Shukla UA, Boutouyrie BX. Pharmacokinetics and pharmacodynamics of the prophylactic dose of enoxaparin once daily over 4 days in patients with renal impairment. Thromb Res. 2002;105(3):225-231.

157. Schmid P, Brodmann D, Odermatt Y, Fischer AG, Wuillemin WA. Study of bioaccumulation of dalteparin at a therapeutic dose in patients with renal insufficiency. J Thromb Haemost. 2009;7(10):1629-1632.

158. Mismetti P, Laporte-Simitsidis S, Navarro C, et al. Aging and venous thromboembolism influence the pharmacodynamics of the anti-factor $\mathrm{Xa}$ and anti-thrombin activities of a low molecular weight heparin (nadroparin). Thromb Haemost. 1998; 79(6):1162-1165.

159. Siguret V, Pautas E, Février M, et al. Elderly patients treated with tinzaparin (Innohep) administered once daily (175 anti-Xa IU/kg): anti-Xa and anti-IIa activities over 10 days. Thromb Haemost. 2000;84(5):800-804.

160. Lim W, Dentali F, Eikelboom JW, Crowther MA. Metaanalysis: low-molecular-weight heparin and bleeding in patients with severe renal insufficiency. Ann Intern Med. 2006; 144(9):673-684.

161. Spinler SA, Inverso SM, Cohen M, Goodman SG, Stringer KA, Antman EM; ESSENCE and TIMI 11B Investigators. Safety and efficacy of unfractionated heparin versus enoxaparin in patients who are obese and patients with severe renal impairment: analysis from the ESSENCE and TIMI 11B studies. Am Heart J. 2003;146(1):33-41.

162. Cestac P, Bagheri H, Lapeyre-Mestre M, et al. Utilisation and safety of low molecular weight heparins: prospective observational study in medical inpatients. Drug Saf. 2003;26(3):197-207.

163. Gerlach AT, Pickworth KK, Seth SK, Tanna SB, Barnes JF. Enoxaparin and bleeding complications: a review in patients with and without renal insufficiency. Pharmacotherapy. 2000;20(7):771-775.

164. Sanderink GJ, Le Liboux A, Jariwala N, et al. The pharmacokinetics and pharmacodynamics of enoxaparin in obese volunteers. Clin Pharmacol Ther. 2002;72(3):308-318.

165. Rabbat CG, Cook DJ, Crowther MA, et al. Dalteparin thromboprophylaxis for critically ill medical-surgical patients with renal insufficiency. J Crit Care. 2005;20(4):357-363.

166. Douketis J, Cook D, Meade M, et al; Canadian Critical Care Trials Group. Prophylaxis against deep vein thrombosis in critically ill patients with severe renal insufficiency with the low-molecular-weight heparin dalteparin: an assessment of safety and pharmacodynamics: the DIRECT study. Arch Intern Med. 2008;168(16):1805-1812.

167. Mahé I, Aghassarian M, Drouet L, et al. Tinzaparin and enoxaparin given at prophylactic dose for eight days in medical elderly patients with impaired renal function: a comparative pharmacokinetic study. Thromb Haemost. 2007;97(4):581586.

168. Lindblad B, Borgström A, Wakefield TW, Whitehouse WM Jr, Stanley JC. Protamine reversal of anticoagulation achieved with a low molecular weight heparin. The effects on eicosanoids, clotting and complement factors. Thromb Res. 1987;48(1):31-40.

169. Massonnet-Castel S, Pelissier E, Bara L, et al. Partial reversal of low molecular weight heparin (PK 10169) anti-Xa activity by protamine sulfate: in vitro and in vivo study during cardiac surgery with extracorporeal circulation. Haemostasis. 1986;16(2):139-146.

170. Racanelli A, Fareed J, Walenga JM, Coyne E. Biochemical and pharmacologic studies on the protamine interactions with heparin, its fractions and fragments. Semin Thromb Hemost. 1985;11(2):176-189.

171. Wolzt M, Weltermann A, Nieszpaur-Los M, et al. Studies on the neutralizing effects of protamine on unfractionated and low molecular weight heparin (Fragmin) at the site of activation of the coagulation system in man. Thromb Haemost. 1995;73(3):439-443.

172. Gatt A, van Veen JJ, Woolley AM, Kitchen S, Cooper P, Makris M. Thrombin generation assays are superior to traditional tests in assessing anticoagulation reversal in vitro. Thromb Haemost. 2008;100(2):350-355.

173. Hirsh J, Levine MN. Low molecular weight heparin. Blood. 1992;79(1):1-17.

174. Crowther MA, Berry LR, Monagle PT, Chan AK. Mechanisms responsible for the failure of protamine to inactivate low-molecular-weight heparin. Br J Haematol. 2002;116(1):178-186.

175. Van Ryn-McKenna J, Cai L, Ofosu FA, Hirsh J, Buchanan MR. Neutralization of enoxaparine-induced bleeding by protamine sulfate. Thromb Haemost. 1990; 63(2):271-274.

176. Bang CJ, Berstad A, Talstad I. Incomplete reversal of enoxaparin-induced bleeding by protamine sulfate. Haemostasis. 1991;21(3):155-160

177. Ng HJ, Koh LP, Lee LH. Successful control of postsurgical bleeding by recombinant factor VIIa in a renal failure patient given low molecular weight heparin and aspirin. Ann Hematol. 2003;82(4):257-258.

178. Byun Y, Singh VK, Yang VC. Low molecular weight protamine: a potential nontoxic heparin antagonist. Thromb Res. 1999;94(1):53-61.

179. Wakefield TW, Andrews PC, Wrobleski SK, et al. Effective and less toxic reversal of low-molecular weight heparin anticoagulation by a designer variant of protamine. J Vasc Surg. $1995 ; 21(5): 839-850$.

180. Wakefield TW, Andrews PC, Wrobleski SK, et al. A [+18RGD] protamine variant for nontoxic and effective reversal of conventional heparin and low-molecular-weight heparin anticoagulation. J Surg Res. 1996;63(1):280-286.

181. Dietrich CP, Shinjo SK, Moraes FA, et al. Structural features and bleeding activity of commercial low molecular weight heparins: neutralization by ATP and protamine. Semin Thromb Hemost. 1999;25(suppl 3):43-50.

182. Kuziej J, Litinas E, Hoppensteadt DA, et al. In vivo neutralization of unfractionated heparin and low-molecularweight heparin by a novel salicylamide derivative. Clin Appl Thromb Hemost. 2010;16(4):377-386.

183. Monreal M, Viñas L, Monreal L, Lavin S, Lafoz E, Angles AM. Heparin-related osteoporosis in rats. A comparative study between unfractioned heparin and a low-molecular-weight heparin. Haemostasis. 1990;20(4):204-207.

184. Mätzsch T, Bergqvist D, Hedner U, Nilsson B, Ostergaard P. Effects of low molecular weight heparin and unfragmented heparin on induction of osteoporosis in rats. Thromb Haemost. 1990;63(3):505-509.

185. Muir J, Hirsh J, Weitz J, Andrew M, Young E, Shaughnessy SG. A histomorphometric comparison of the effects of heparin and low-molecular-weight heparin on cancellous bone in rats. Blood. 1997;89(9):3263-3242.

186. Kock HJ, Handschin AE. Osteoblast growth inhibition by unfractionated heparin and by low molecular weight heparins: an in-vitro investigation. Clin Appl Thromb Hemost. $2002 ; 8(3): 251-255$.

187. Folwarczna J, Janiec W, Gawor M, Pytlik M, KaczmarczykSedlak I, Nowi ska B. Effects of enoxaparin on histomorphometric parameters of bones in rats. Pol J Pharmacol. 2004;56(4):451-457. 
188. Casele HL, Laifer SA. Prospective evaluation of bone density in pregnant women receiving the low molecular weight heparin enoxaparin sodium. J Matern Fetal Med. 2000;9(2): 122-125.

189. Pettilä V, Leinonen P, Markkola A, Hiilesmaa V, Kaaja R. Postpartum bone mineral density in women treated for thromboprophylaxis with unfractionated heparin or LMW heparin. Thromb Haemost. 2002;87(2):182-186.

190. Wawrzysnka L, Tomkowski WZ, Przedlacki J, Hajduk B, Torbicki A. Changes in bone density during long-term administration of low-molecular-weight heparins or acenocoumarol for secondary prophylaxis of venous thromboembolism. Pathophysiol Haemost Thromb. 2003;33(2): 64-67.

191. Lefkou E, Khamashta M, Hampson G, Hunt BJ. Review: Low-molecular-weight heparin-induced osteoporosis and osteoporotic fractures: a myth or an existing entity? Lupus. 2010;19(1):3-12.

192. Choay J, Lormeau JC, Petitou M, Sinaÿ P, Fareed J. Structural studies on a biologically active hexasaccharide obtained from heparin. Ann N Y Acad Sci. 1981;370:644-649.

193. Thunberg L, Bäckström G, Lindahl U. Further characterization of the antithrombin-binding sequence in heparin. Carbohydr Res. 1982;100:393-410.

194. Choay J. Biologic studies on chemically synthesized pentasaccharide and tetrasaccharide fragments. Semin Thromb Hemost. 1985;11(2):81-85.

195. Atha DH, Lormeau JC, Petitou M, Rosenberg RD, Choay J. Contribution of 3-O- and 6-O-sulfated glucosamine residues in the heparin-induced conformational change in antithrombin III. Biochemistry. 1987;26(20):6454-6461.

196. Depasse F, Gilbert M, Goret V, Rolland N, Samama MM. Anti-Xa monitoring: inter-assay variability. Thromb Haemost. 2000;84(6):1122-1123.

197. Kitchen S, Iampietro R, Woolley AM, Preston FE. Anti Xa monitoring during treatment with low molecular weight heparin or danaparoid: inter-assay variability. Thromb Haemost. 1999;82(4):1289-1293.

198. Boneu B, Necciari J, Cariou R, et al. Pharmacokinetics and tolerance of the natural pentasaccharide (SR90107/ Org31540) with high affinity to antithrombin III in man. Thromb Haemost. 1995;74(6):1468-1473.

199. Donat F, Duret JP, Santoni A, et al. The pharmacokinetics of fondaparinux sodium in healthy volunteers. Clin Pharmacokinet. 2002;41(suppl 2):1-9.

200. Lieu C, Shi J, Donat F, et al. Fondaparinux sodium is not metabolised in mammalian liver fractions and does not inhibit cytochrome P450-mediated metabolism of concomitant drugs. Clin Pharmacokinet. 2002;41(suppl 2): 19-26.

201. Paolucci F, Claviés MC, Donat F, Necciari J. Fondaparinux sodium mechanism of action: identification of specific binding to purified and human plasma-derived proteins. Clin Pharmacokinet. 2002;41(suppl 2):11-18.

202. Bijsterveld NR, Moons AH, Boekholdt SM, et al. Ability of recombinant factor VIIa to reverse the anticoagulant effect of the pentasaccharide fondaparinux in healthy volunteers. Circulation. 2002;106(20):2550-2554.

203. Savi P, Chong BH, Greinacher A, et al. Effect of fondaparinux on platelet activation in the presence of heparindependent antibodies: a blinded comparative multicenter study with unfractionated heparin. Blood. 2005;105(1): 139-144.

204. Rota E, Bazzan M, Fantino G. Fondaparinux-related thrombocytopenia in a previous low-molecular-weight heparin (LMWH)-induced heparin-induced thrombocytopenia (HIT). Thromb Haemost. 2008;99(4):779-781.
205. Warkentin TE, Maurer BT, Aster RH. Heparin-induced thrombocytopenia associated with fondaparinux. $N$ Engl J Med. 2007;356(25):2653-2655.

206. Warkentin TE, Cook RJ, Marder VJ, et al. Anti-platelet factor 4/heparin antibodies in orthopedic surgery patients receiving antithrombotic prophylaxis with fondaparinux or enoxaparin. Blood. 2005;106(12):3791-3796.

207. Kuo KH, Kovacs MJ. Fondaparinux: a potential new therapy for HIT. Hematology. 2005;10(4):271-275.

208. Blackmer AB, Oertel MD, Valgus JM. Fondaparinux and the management of heparin-induced thrombocytopenia: the journey continues. Ann Pharmacother. 2009;43(10):1636-1646.

209. Parody R, Oliver A, Souto JC, Fontcuberta J. Fondaparinux (ARIXTRA) as an alternative anti-thrombotic prophylaxis when there is hypersensitivity to low molecular weight and unfractionated heparins. Haematologica. 2003;88(11): ECR32.

210. Matziolis G, Perka C, Disch A, Zippel H. Effects of fondaparinux compared with dalteparin, enoxaparin and unfractionated heparin on human osteoblasts. Calcif Tissue Int. 2003;73(4):370-379.

211. Handschin AE, Trentz OA, Hoerstrup SP, Kock HJ, Wanner GA, Trentz O. Effect of low molecular weight heparin (dalteparin) and fondaparinux (Arixtra) on human osteoblasts in vitro. Br J Surg. 2005;92(2):177-183.

212. Lagrange F, Vergnes C, Brun JL, et al. Absence of placental transfer of pentasaccharide (Fondaparinux, Arixtra) in the dually perfused human cotyledon in vitro. Thromb Haemost. 2002;87(5):831-835.

213. Dempfle CE. Minor transplacental passage of fondaparinux in vivo. N Engl J Med. 2004;350(18):1914-1915.

214. Toschi V, Lettino M, Gallo R, Badimon JJ, Chesebro JH. Biochemistry and biology of hirudin. Coron Artery Dis. 1996;7(6):420-428.

215. Wallis RB. Hirudins: from leeches to man. Semin Thromb Hemost. 1996;22(2):185-196.

216. Lefèvre G, Duval M, Gauron S, et al. Effect of renal impairment on the pharmacokinetics and pharmacodynamics of desirudin. Clin Pharmacol Ther. 1997;62(1):50-59.

217. Tardy B, Lecompte T, Boelhen F, et al; GEHT-HIT Study Group. Predictive factors for thrombosis and major bleeding in an observational study in 181 patients with heparininduced thrombocytopenia treated with lepirudin. Blood. 2006;108(5):1492-1496.

218. Maraganore JM, Bourdon P, Jablonski J, Ramachandran KL, Fenton JW II. Design and characterization of hirulogs: a novel class of bivalent peptide inhibitors of thrombin. Biochemistry. 1990;29(30):7095-7101.

219. Skrzypczak-Jankun E, Carperos VE, Ravichandran KG, Tulinsky A, Westbrook M, Maraganore JM. Structure of the hirugen and hirulog 1 complexes of alpha-thrombin. J Mol Biol. 1991;221(4):1379-1393.

220. Witting JI, Bourdon P, Maraganore JM, Fenton JW II. Hirulog-1 and -B2 thrombin specificity. Biochem J. 1992;287(pt 2):663-664.

221. Fox I, Dawson A, Loynds P, et al. Anticoagulant activity of Hirulog, a direct thrombin inhibitor, in humans. Thromb Haemost. 1993;69(2):157-163.

222. Robson $\mathrm{R}$. The use of bivalirudin in patients with renal impairment. J Invasive Cardiol. 2000;12(suppl F):33F-6.

223. White HD. Pharmacological and clinical profile of bivalirudin in the treatment of patients with acute coronary syndrome. Expert Opin Drug Metab Toxicol. 2009;5(5): 529-538.

224. Banner DW, Hadváry P. Inhibitor binding to thrombin: x-ray crystallographic studies. Adv Exp Med Biol. 1993;340: 27-33. 
225. Hursting MJ, Alford KL, Becker JC, et al. Novastan (brand of argatroban): a small-molecule, direct thrombin inhibitor. Semin Thromb Hemost. 1997;23(6):503-516.

226. Swan SK, Hursting MJ. The pharmacokinetics and pharmacodynamics of argatroban: effects of age, gender, and hepatic or renal dysfunction. Pharmacotherapy. 2000;20(3): 318-329.

227. Warkentin TE, Greinacher A, Craven S, Dewar L, Sheppard JA, Ofosu FA. Differences in the clinically effective molar concentrations of four direct thrombin inhibitors explain their variable prothrombin time prolongation. Thromb Haemost. 2005;94(5):958-964.

228. Arpino PA, Demirjian Z, Van Cott EM. Use of the chromogenic factor $\mathrm{X}$ assay to predict the international normalized ratio in patients transitioning from argatroban to warfarin. Pharmacotherapy. 2005;25(2):157-164.

229. Bartholomew J. Transition to an oral anticoagulant in patients with heparin-induced thrombocytopenia. Chest. 2005;127(suppl 2):27S-34S.

230. Hursting MJ, Lewis BE, Macfarlane DE. Transitioning from argatroban to warfarin therapy in patients with heparin-induced thrombocytopenia. Clin Appl Thromb Hemost. 2005;11(3):279-287.

231. Sørensen B, Ingerslev J. A direct thrombin inhibitor studied by dynamic whole blood clot formation. Haemostatic response to ex-vivo addition of recombinant factor VIIa or activated prothrombin complex concentrate. Thromb Haemost. 2006;96(4):446-453. 